\title{
Recombinase technology: applications and possibilities
}

\author{
Yueju Wang • Yuan-Yeu Yau • \\ Donna Perkins-Balding $\cdot$ James G. Thomson
}

Received: 27 August 2010/Revised: 6 October 2010/Accepted: 8 October 2010/Published online: 24 October 2010

(C) The Author(s) 2010. This article is published with open access at Springerlink.com

\begin{abstract}
The use of recombinases for genomic engineering is no longer a new technology. In fact, this technology has entered its third decade since the initial discovery that recombinases function in heterologous systems (Sauer in Mol Cell Biol 7(6):2087-2096, 1987). The random insertion of a transgene into a plant genome by traditional methods generates unpredictable expression patterns. This feature of transgenesis makes screening for functional lines with predictable expression labor intensive and time consuming. Furthermore, an antibiotic resistance gene is often left in the final product and the potential escape of such resistance markers into the environment and their potential consumption raises consumer concern. The use of site-specific recombination technology in plant genome manipulation has been demonstrated to effectively
\end{abstract}

Communicated by R. Reski.

A contribution to the Special Issue: Plant Biotechnology in Support of the Millennium Development Goals.

\section{Y. Wang}

Department of Natural Sciences, Northeastern State University, Broken Arrow, OK 74014, USA

D. Perkins-Balding

Biology Department, Macon State College,

Macon, GA 31206, USA

\section{Y.-Y. Yau}

Department of Plant and Microbial Biology,

Plant Gene Expression Center, USDA-ARS,

University of California-Berkeley, 800 Buchanan St.,

Albany, CA 94710, USA

\section{J. G. Thomson ( $\square)$}

Crop Improvement and Utilization Unit, USDA-ARS WRRC,

800 Buchanan St., Albany, CA 94710, USA

e-mail: James.Thomson@ars.usda.gov resolve complex transgene insertions to single copy, remove unwanted DNA, and precisely insert DNA into known genomic target sites. Recombinases have also been demonstrated capable of site-specific recombination within non-nuclear targets, such as the plastid genome of tobacco. Here, we review multiple uses of site-specific recombination and their application toward plant genomic engineering. We also provide alternative strategies for the combined use of multiple site-specific recombinase systems for genome engineering to precisely insert transgenes into a pre-determined locus, and removal of unwanted selectable marker genes.

Keywords Site-specific recombination - Transgenic plant $\cdot$ Integration $\cdot$ Excision $\cdot$ RMCE

\section{Introduction}

In 1983, four groups published independent investigations introducing foreign genes into plants through cell transformation, thereby creating the first transgenic plants (Bevan et al. 1983; Fraley et al. 1983; Herrera-Estrella et al. 1983; Murai et al. 1983). Since then, countless genes, RNAs and regulatory elements have been introduced and studied in various transgenic plants. Several important agronomic crops such as cotton, soybean, canola and maize, with commercially useful traits, have been genetically modified (GM) and released for commercial production (Moeller and Wang 2008). Because of the enhanced quality of the plants, GM technology has had a significant and positive impact on farm income derived from a combination of increased productivity and efficiency gains. In 2007, the direct global farm income benefit from biotech crops was $\$ 10.1$ billion. Since 1996, farm incomes have increased by $\$ 44.1$ billion 
(Brookes and Barfoot 2009). Advancement in technologies for plant genetic engineering have significantly improved as well as transformation procedures, which have become routine for a wide variety of plant species (Moeller and Wang 2008). These sophisticated breeding techniques and GM technology have not only had positive impact on food producers, but also there has been a decreasing trend in global hunger due, in part, to the decreased cost and availability of superior food crops. Although the global hunger index is continually decreasing the ability to enhance food crops for better quality and yield through genetic modification will undoubtedly play an important role in addressing this concern.

Agrobacterium-mediated and particle bombardment methods are the two most commonly used techniques for crop transformation. However, both methods are dependent on the random nature of the transgene integration. The phenomenon of multiple copy transgene insertion leading to gene silencing and unpredictable expression is often encountered with transgenic plants. The isolation of stable transgenic lines with the desired level of transgene expression is labor intensive and costly. It is often necessary to screen hundreds of independently transformed plants to identify those with suitable transgene structure and expression (Ow 2005). Therefore, many research endeavors are focused on goals to eliminate random DNA integration and/or reduce the frequency of multi-copy transgene insertions, thus reducing or eliminating events that exhibit unreliable transgene expression (Ow 2005). As more genes are discovered through whole genome sequencing from different organisms including important economic plants, applications to improve crop traits, (e.g. rice and wheat) will become an import focus in the postgenomic era. How to express or manipulate multiple genes in the plant genome is still a major technical hurdle that is difficult to achieve (Halpin 2005). Site-specific recombination is a promising technology that can be used to address these challenges of crop genome engineering. In this review, we examine previous studies and discuss recent advances to the applications of site-specific recombinase technology. We also propose a novel strategy to achieve both site-specific gene integration and deletion of unneeded DNA through the combined use of two irreversible site-specific recombination systems.

\section{Recombinase types and their modes of action}

Site-specific recombinase systems were discovered in bacteria and yeast and found to facilitate a number of biological functions, including the phase variation of certain bacterial virulence factors and the integration of bacteriophage into the host genome. Site-specific recombination occurs at a specific sequence or recognition site and involves cleavage and reunion leading to integration, deletion or inversion of a DNA fragment without the gain or loss of nucleotides. Whether its integration, deletion or inversion of a DNA fragment, orientation of the recognition sites determines the mode of action (Grindley et al. 2006).

The recombinase super family can be split into two fundamental groups, the tyrosine and serine recombinases. This division is based on the active amino acid (Tyr or Ser) within the catalytic domain of the enzymes in each family. Both families can be further subdivided into unique members based on either size or mode of recombinase action (Fig. 1). The first and best-characterized group has members that include the Cre-lox (Sauer and Henderson 1990), FLP-FRT (Golic and Lindquist 1989) and R-RS (Onouchi et al. 1991) systems where Cre, FLP and R are bidirectional tyrosine recombinases and lox, FRT, and $R S$ are the respective identical DNA recognition sites (i.e. sequences the enzymes recognize to perform recombination). Within this bidirectional tyrosine sub-family, the recombinase-mediated genetic cross-over occurs between the two identical recognition sites. Because of the identical nature of the recognition sites the recombination reaction is fully reversible, although intra-molecular recombination (excision) is highly favored over inter-molecular reactions (integration).

The unidirectional tyrosine sub-family has non-identical recognition sites typically known as $a t t B$ (attachment site bacteria) and attP (attachment site phage) and performs irreversible recombination in the absence of a helper protein, termed an excisionase. The unidirectional tyrosine recombinases that have been shown to be useful for genome manipulation include HK022 (Kolot et al. 1999; Gottfried et al. 2005) and a modified form of $\lambda$ (Christ and Droge 2002).

The serine recombinase family also has two distinct members with the division being based on size of the enzyme. The small serine sub-family contains $\beta$-six (Diaz et al. 2001), $\gamma \delta$-res (Schwikardi and Droge 2000), CinHRS2 (Kholodii 2001; Thomson and Ow 2006) and ParAMRS (Gerlitz et al. 1990; Thomson et al. 2009), where $\beta$, $\gamma \delta, \mathrm{CinH}$ and ParA are small serine recombinases, and six, res, $R S 2$ and $M R S$ are the respective DNA recognition sites. While recombination mediated by these small serine recombinases (a.k.a. resolvases) utilizes identical recognition sites only intra-molecular excision events are observed. Studies have determined that due to conformational strain small serine recombinases cannot facilitate inter-molecular integration (Mouw et al. 2008). Therefore, an excision event mediated by the small serine recombinases is considered irreversible.

The large serine sub-family is represented by phiC31 (Thomason et al. 2001; Rubtsova et al. 2008), TP901-1 


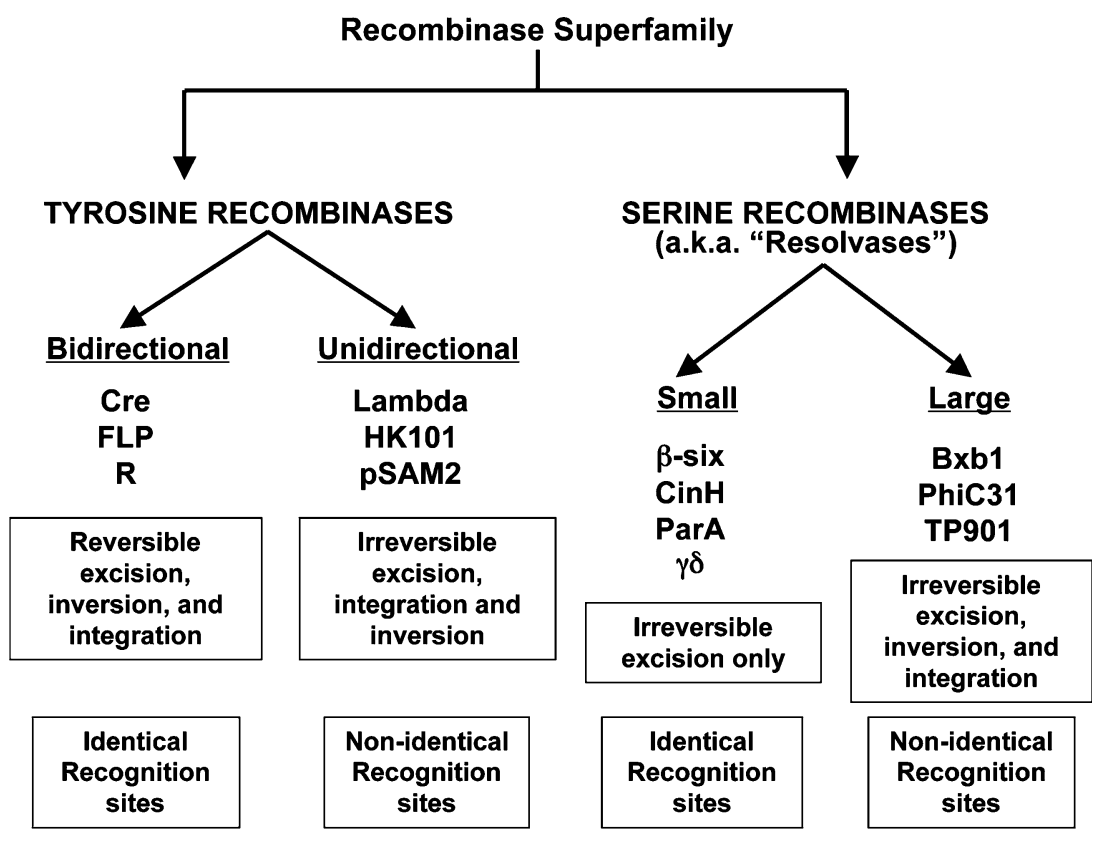

Fig. 1 Diagram of the recombinase super family. The two major families are divided based on the active amino acid of the catalytic domain, either a tyrosine or a serine. The tyrosine family can be divided into members that utilize identical and non-identical recognition sites. Those depend on identical recognition sites are the bidirectional tyrosine and are reversible in action while the unidirectional tyrosine that utilize non-identical sites are irreversible.

(Stoll et al. 2002), R4 (Olivares et al. 2001) and Bxb1 (Kim et al. 2003; Keravala et al. 2006; Thomson and Ow 2006). These enzymes act on two recognition sites that differ in sequence, typically known as recognition sites $a t t B$ and $a t t P$, to yield hybrid product sites known as $a t t L$ and $a t t R$. Excision, inversion or integration reactions can occur, but because the recognition site sequences of $a t t B$ and $a t t P$ are changed to att $L$ and $a t t R$, the reverse reaction cannot occur. A reversal of the reaction is only possible though the addition of a second protein, the corresponding excisionase (Thorpe et al. 2000; Ghosh et al. 2006).

\section{Uses of recombinases for excision}

Site-specific recombination was among the first methods used to create transgenic plants without retention of a selectable marker transgene (Dale and Ow 1991; Russell et al. 1992) (Fig. 2). Adoption of this technology could potentially eliminate the movement of selectable marker transgenes within the environment. Removal of the selectable marker also allows reuse of the same selection regime for subsequent rounds of gene transfer. A number of recombinase-mediated marker deletion strategies have been reported in model plants (Dale and Ow 1991; Albert et al. 1995; Gleave et al. 1999; Sugita et al. 1999, 2000a, b; Endo

Members of the serine family are irreversible in action but can be further divided into "large" ( $\sim 60 \mathrm{kDa})$ or "small" ( $23 \mathrm{kDa})$ families based on enzyme size. While the "small' members utilized identical recognition sites, they appear only capable of excision due to topological constraints. The "large" serine is efficient at excision, integration and inversion. Examples of each subfamily are listed and their mode of action and the nature of the recognition sites are shown

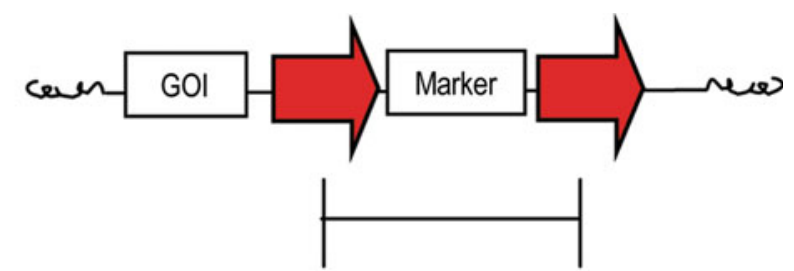

recombinase-mediated excision



Fig. 2 Schematic representation of recombinase-mediated selectable marker removal. The marker gene is flanked by directly oriented recombinase recognition sites (red arrows). The excision event removes the DNA between the associated recognition sites leaving the external DNA, such as the gene of interest (GOI) intact and a single recognition site behind in the genome. The non-replicating circular DNA fragment is lost. The recombinase can be provided in cis or in trans-not shown

et al. 2001, 2002; Hohn et al. 2001; Hare and Chua 2002; Nanto et al. 2005; Nanto and Ebinuma 2008; Nanto et al. 2009; Thomson et al. 2009, 2010), as well as in crop species 
(Lyznik et al. 1996; Srivastava et al. 1999; Ebinuma and Komamine 2001; Hoa et al. 2002; Matsunaga et al. 2002; Gilbertson et al. 2003; Srivastava and Ow 2003; Zhang et al. 2003; Kerbach et al. 2005; Radhakrishnan and Srivastava 2005; Sreekala et al. 2005; Ballester et al. 2006; Cao et al. 2006; Chawla et al. 2006; Cuellar et al. 2006; Djukanovic et al. 2008; Hu et al. 2008; Kempe et al. 2010).

In 2006, the first commercial marker-free corn LY038, developed by Monsanto with Cre-lox system, obtained USDA approval (Ow 2007). LY038 contains high lysine content providing supplemental lysine for poultry and swine diets (Comprehensive Reviews in Food Science and Food Safety 2008). To produce the LY038, a plasmid containing the cordapA (coding region of the dihydrodipicolinate synthase gene from Corynebacterium glutamicum) and kanamycin selectable marker gene nptII coding sequences was introduced into the maize H99 through biolistic particle bombardment transformation. The nptII cassette was flanked by loxP sites, in direct orientation for Cre-mediated excision. The selected cordapA-nptII transgenic maize was crossed with another corn line expressing the Cre recombinase. Recombinase-mediated excision removed the nptII gene cassette leaving only the cordapA gene cassette. However, to produce these marker-free transgenic plants, involved crossing the recombinaseexpressing lines to the target line, selecting for complete excision, and finally segregation of the recombinase gene. Although it is feasible to produce marker-free transgenic crop plants using this process, it may not be optimal due to constraints on time, labor and the substantial financial resources needed. Generation of transgenic crops in this manner requires multiple generations and may not be practical in species with longer generation times such as trees, or in other crops such as potato, which are propagated asexually.

To shorten and simplify the process of selectable marker excision, various groups have designed one-step autoexcision strategies for DNA removal (Fig. 3). In these strategies the gene(s) of interest (GOI), the marker gene, and the recombinase, are cloned into a single construct with the recombinase gene under the control of an inducible promoter (for example, heat shock promoter HSP81-1; Takahashi et al. 1992; Hoff et al. 2001; Liu et al. 2005). The selection gene is placed in a cassette flanked by directly oriented recognition sites, while the gene of interest is inserted outside of the region flanked by recognition sites. After transformation, the putative transgenic plants are induced to initiate the expression of a recombinase, such as Cre. Other inducible systems have been constructed by the fusing Cre to various ligand binding domains (Logie and Stewart 1995; Metzger et al. 1995; Joubès et al. 2004). Cre has also been fused to the estrogen hormone receptor, which in the absence of the target

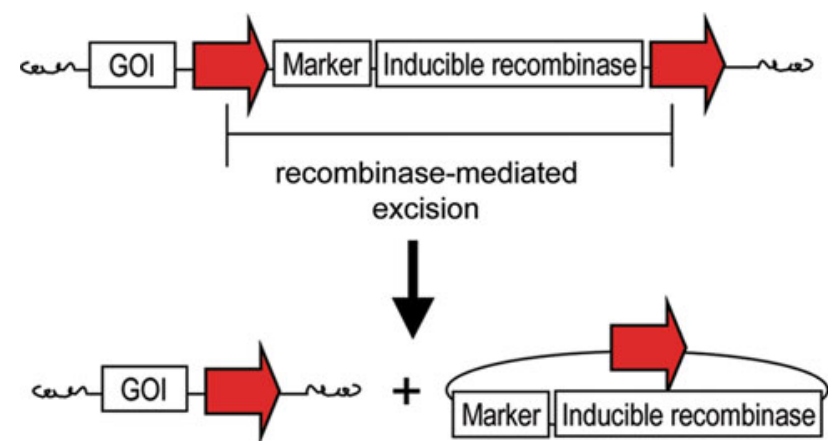

Fig. 3 Schematic representation of an inducible recombinase-mediated selectable marker removal strategy. The marker and recombinase genes are flanked by directly oriented recombinase recognition sites (red arrows). In this strategy the recombinase gene is present in the genome and can be externally or developmentally induced. Activation of the recombinase causes excision of the recombinase and marker gene, leaving behind only the gene of interest (GOI), a single recognition site and a non-replicating circular DNA fragment

hormone can limit access of the recombinase fusion protein to the nucleus and thereby inhibit recombination events (Feil et al. 1996; Kellendonk et al. 1996; Brocard et al. 1998; Danielian et al. 1998). In the presence of the hormone inducer, a recombinase-mediated excision event deletes the intervening region between directly oriented recognition sites (e.g. loxP) removing both the recombinase and the selectable marker genes (Fig. 3). An autoexcision strategy like this has been applied to Arabidopsis (Zuo et al. 2001), tomato (Zhang et al. 2006), maize (Zhang et al. 2003), rice and aspen (Ebinuma and Komamine 2001; Matsunaga et al. 2002; Sreekala et al. 2005) and tobacco (Sugita et al. 2000a, b; Endo et al. 2002; Liu et al. 2005; Wang et al. 2005). As chemicals or heat shock treatments are required for recombinase activation, marker gene deletion utilizing these treatments may be limited to certain plant species and/or may present complications for the transformation process due to premature recombinase expression ( $\mathrm{Li}$ et al. 2007). Situations to be considered are if the system is leaky producing uninduced expression of the recombinase, which can lead to undesirable excision. This can be the result of either promoter mis-regulation or genomic positional effect. Then again, weak-induced expression of the recombinase can also result giving incomplete transgene excision.

An alternative approach to the previously described strategy is the use of a developmentally inducible promoter to activate recombinase expression only within specific organs/tissues during development. Various germline-specific promoters have been employed for recombinase expression (Mlynárová et al. 2006; Li et al. 2007; Luo et al. 2007; Verweire et al. 2007; Kopertekh et al. 2010); see Gidoni et al. (2008) for a detailed listing of promoters used to drive recombinases. This strategy may be easier to 
implement than the inducible systems since they do not require extra steps for recombinase expression and potentially enabling higher rates of excision. Employment of the developmentally regulated recombinase-mediated excision strategy has provided a containment system to prevent transgene movement via pollen by activating recombinase expression during pollen development mediating the excision of transgenes from the genome (Mlynárová et al. 2006; Luo et al. 2007). This technique could potentially reduce the risk of transgene flow within the environment, eliminating the adventitious presence of transgenes in non-GM crops or related wild species. Li et al. (2007) demonstrated the feasibility of this process in seed with a self-activating excision system in soybean using an embryo-specific promoter to drive the temporal expression of the recombinase Cre.

Another strategy is to provide transient expression of the recombinase. The most direct approach is to transform cells directly with a recombinase expression cassette (Albert et al. 1995; Araki et al. 1995; Vergunst et al. 1998; Srivastava and Ow 2001). The recombinase is transiently expressed in cells and should not stably integrated into the genome of the host cell. However, Srivastava and Ow (2001) have measured genomic integration of the recombinase gene in $40 \%$ of host cells that underwent recombinase-mediated excision. Two published expression vectors have been designed specifically for transient recombinase expression: one utilizes A. tumefaciens transformation proteins (Vergunst et al. 2000; Kopertekh and Schiemann 2005), the other is a Cre/virus vector (Kopertekh et al. 2004a, b; Jia et al. 2006). Other options that are known to control transient recombinase expression include direct transformation of recombinase mRNA (De Wit et al. 1998) and use of peptides to facilitate direct cellular uptake of the recombinase protein (Peitz et al. 2002).

\section{Resolution of transgene concatomers}

A unique feature of recombinase-mediated excision is its ability to resolve complex insertion sites containing multiple transgenes down to single copy structures. The technique, originally demonstrated in wheat by Srivastava et al. (1999), involved four multi-copy transgenic lines being resolved to single copy by Cre-mediated excision. This strategy requires the presence of at least one recognition site within the transgene structure, although two sites with inverted orientation flanking the entire T-DNA appear to be the optimal configuration. Tandem arrays will be excised due to the presence of the multiple recognition sites in direct orientation. Recombinase-meditated excision will continue until a single recognition site is left (Fig. 4). The possibility does exist for fragmented T-DNA to be located outside the outer most recognition site but this should be

(a)

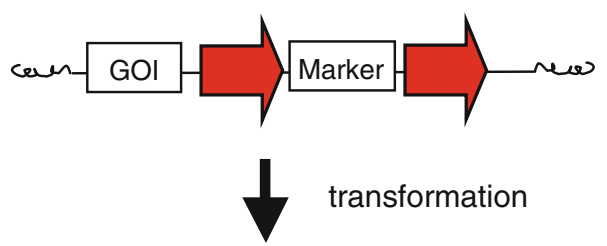

(b)

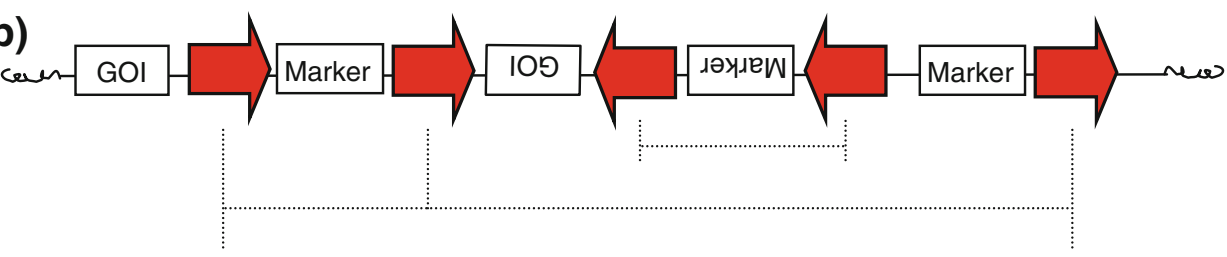

(c)
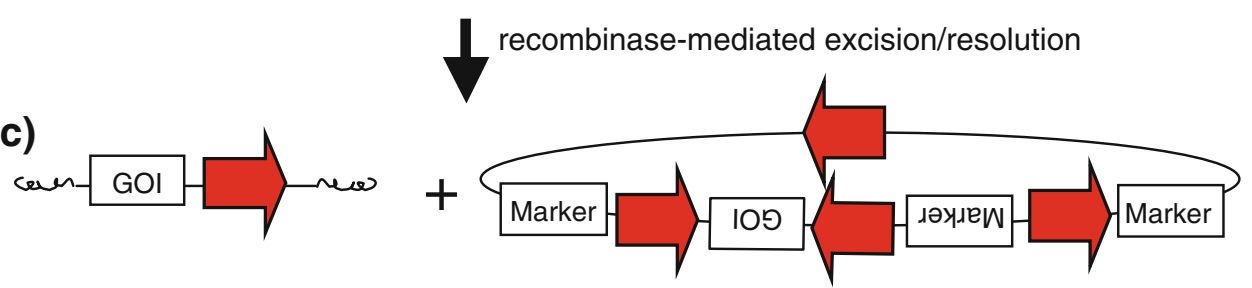

Fig. 4 Schematic representation of a recombinase-mediated resolution event. This technique uses the recombinases' capacity to excise DNA from between any two directly oriented recognition sites (red arrows) thereby removing the intervening or 'complexed' DNA from the genome. a The initial construct used for transformation. b Complex transgene integration. Dotted line designates all possible excision events mediated by directly oriented recognition sites. c Transgene resolution to a single recognition site in the genome and non-replicating circular fragment. DNA fragments present without flanking recognition sites will not be removed. The recombinase can be provided in cis or in trans-not shown. All possible excision products-not shown 
detectable with proper molecular characterization. Single copy transgene structures are generally the most soughtafter due to their consistent expression pattern, stability within the genome, heritability, low occurrence of silencing, and simplicity of structural characterization (Day et al. 2000). A study by Chawla et al. (2006) demonstrated that rice with multicopy transgene inserts, initially silenced for expression, recovered expression when resolved by segregation to a single genomic copy. This procedure has the advantage of lowering the total number of transgenic plants required in order to find a properly expressing single copy line that is heritable.

In recent years, a number of novel recombinase systems have been identified that show the ability to excise DNA in eukaryotic cells. These include phiC31 (Kempe et al. 2010; Thomason et al. 2001, 2010), Bxb1, TP901-1 and U153 (Keravala et al. 2006; Thomson and Ow 2006) of the large serine recombinase family and $\mathrm{CinH}, \mathrm{ParA}, \mathrm{Tn} 1721$ and Tn5053 from the small serine resolvase family (Thomson and Ow 2006; Thomson et al. 2009). In the S. pombe system described by Thomson and Ow (2006), the recombinases with the most effective rates of genomic excision are Bxb1, CinH, ParA and phiC31 at 100, 95, 97 and $91 \%$, respectively. Currently, phiC 31 is patent protected by the USDA (US Patent 6,746,870) while the remaining recombinases have a USDA patent pending (US Patent application 20060046294). This technology is publicly available for research purposes and non-exclusive licenses for commercial uses are granted. As can be seen, recombinase-mediated excision offers many benefits over traditional genomic engineering methods, namely the removal of unwanted DNA, recycling of selectable markers and resolution of complex transgene concatomers to single copy stable loci. Other current reviews are available on the topic of recombinase-mediated excision strategies in plants (Gidoni et al. 2008; Moon et al. 2009) and 'clean gene' technology (Afolade 2007).

\section{Chromosomal engineering}

Physical distance between recognition sites does not appear to limit the capacity of the recombinase, although larger distances (megabases) will lower the efficiency of recombination. This feature of site-specific recombination has made planned chromosomal rearrangements a feasible option for genetic engineering. Large deletions, duplications or chromosomal translocations allow the study of known genetic diseases such as Downs syndrome, SmithMagenis syndrome, Cri-du-chat, and Charcot-Marie-Thooth type 1A (Korenberg et al. 1994; Chen et al. 1997; Lupski 1998). Cre-induced site-specific translocations have been reported in ES cells (Deursoen et al. 1995) and plants
(Qin et al. 1994), with site-specific translocation being shown to occur 1:1,200-2,400 (non-random:random) in ES cells that express the Cre protein. As orientation of the loxP sites will determine the type of recombination event observed, and since eukaryotes are diploid, complications can occur. With two loxP sites located on a single chromosome in directly repeated orientation a deletion event is expected, but duplication events have also been detected (Medberry et al. 1995; Ramierez-Solis et al. 1995; van Deursen et al. 1995; Uemura et al. 2010). The deletion/ duplication events result from a non-sister chromatid recombination event that generates a series of balanced and unbalanced chromatids. The difference in chromosomal relation (i.e. intra-chromosomal, homologous, non-homologous) and loxP placement appears to govern the frequency of recombination (Burgess and Kleckner 1999). A more controlled and effective form of chromosomal deletion and/or duplication involves the use of a temporalspecific promoter, for the synaptonemal complex protein1 (SYCP1). In the spermatocytes of mice during meiosis, the homologous chromosomes are tightly paired in the synaptonemal complex. The SYCP1 promoter drives Cre expression generating efficient deletion and duplication events due to close proximity of the chromosomes in the synaptonemal complex (Herault et al. 1998). With the loxP sites in the opposite orientation and located on the same chromosome, an inversion event is generated. This form of chromosomal rearrangement can be used to study genetic abnormalities and establish balanced lethal systems to facilitate stock maintenance (Zheng et al. 1999). This loxP orientation can also lead to unequal recombination between sister chromatids, generating dicentric and acentric chromosomes (Uemura et al. 2010). Chromosomes in these configurations are lost during the next cell division, generating monosomic cells (Lewandoski and Martin 1997; Uemura et al. 2010).

Placement of the loxP sites in the same orientation on a non-homologous chromosome can lead to balanced and unbalanced chromosomal translocations. These rearrangements have been used to study the effects of inappropriate regulation of spatial and temporal gene expressions leading to various forms of human cancer, developmental abnormalities and genetic diseases (Van Deursen et al. 1995; Smith et al. 1995). A translocation experiment was performed in tobacco plants to determine efficiencies in programmed chromosomal rearrangements. One loxP/ hygromycin open reading frame containing chromosome was allowed to recombine in the presence of a second $35 \mathrm{~S}$ promoter/loxP-containing chromosome. When Cre protein was introduced into the in vivo system, $2.5 \%$ of the resulting plants were hygromycin resistant (Qin et al. 1994). It has also been shown that chromosomal translocations can be induced across species. Protoplasts from two 
species of plants (Arabidopsis and tobacco) were fused in culture and induced for a Cre-mediated recombination event. A successful recombination event joined the promoter region with the open reading frame of the resistance gene hygomycin. Resistant calli were analyzed and found to contain the junction between the Arabidopsis of chromosome $\mathrm{V}$ with a chromosome from the tobacco genome. Unfortunately after the calli were grown and self fertilized, it was determined that the interspecies transferred arm was not maintained (Koskinsky et al. 2000).

While as yet undemonstrated in crops, the use of chromosomal recombination offers the possibility of speeding introgression between laboratory transformation competent lines and elite high production lines by breaking associated linkage drag thereby speeding the transfer of genomic modifications from lab to elite lines for agronomic cultivation as proposed by Ow (2005) (Fig. 5).

\section{Benefits of recombinase-mediated integration}

Various factors appear to effect transgene expression and stability. The most prominent of these are the genomic location of transgene integration (positional effect) and the complexity of integration. Transgene expression may be increased, decreased or mis-regulated depending on surrounding genomic elements. The integration pattern refers to aspects of the transgene such as, its final structural configuration, number of copies, presence of transgene fragments, and number of loci where transgene insertion occurred. In genomic engineering the ability to insert a single copy transgene into a predicted location is most desirable. The single copy transgene produces comparable gene expression levels and effects (Day et al. 2000) by reducing or even eliminating the 'position effect' (Clark et al. 1994; Meyer 2000), mosaicism (Burdon and Wall 1992), genomic instability (Collick et al. 1996; Maqbool and Chritou 1999), gene variegation (Dobie et al. 1997) and silencing (Henikoff 1998; Selker 1999; Muskens et al. 2000). Furthermore, single copy transgene inserts give more reliable and reproducible expression than those with multicopy insertions (Day et al. 2000; Iyer et al. 2000). Because of these benefits considerable effort and time is spent isolating and characterizing single copy lines for predictability of expression and inheritance. These single copy insertion lines also offer a much simpler molecular characterization, which, in turn, may ease the process of federal de-regulation (Ow 2007).

Recombinase-mediated integration can be used to insert a single copy of foreign DNA into predetermined locations within a genome (Sauer and Henderson 1990; O'Gorman et al. 1991). This technology has allowed the production of precisely engineered transgenic plants and has been reported to function in Arabidopsis (Louwerse et al. 2007; Vergunst and Hooykaas 1998; Vergunst et al. 1998), aspen (Fladung and Becker 2010), tobacco (Albert et al. 1995; Choi et al. 2000; Day et al. 2000; Nanto et al. 2005, 2009; Nanto and Ebinuma 2008) maize (Baszczynski et al. 2003; Kerbach et al. 2005), rice (Srivastava and Ow 2002; Srivastava et al. 2004; Chawla et al. 2006), soybean (Li et al. 2009) and the plastid genome of tobacco (Lutz et al. 2004). Rates of integration have been documented from (a)

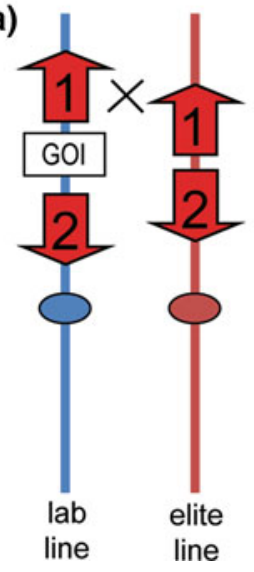

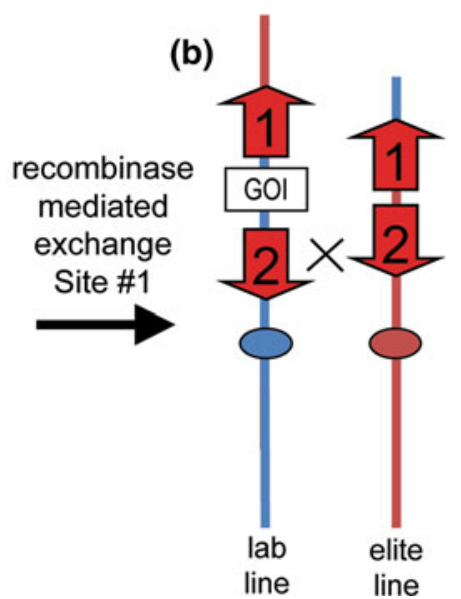

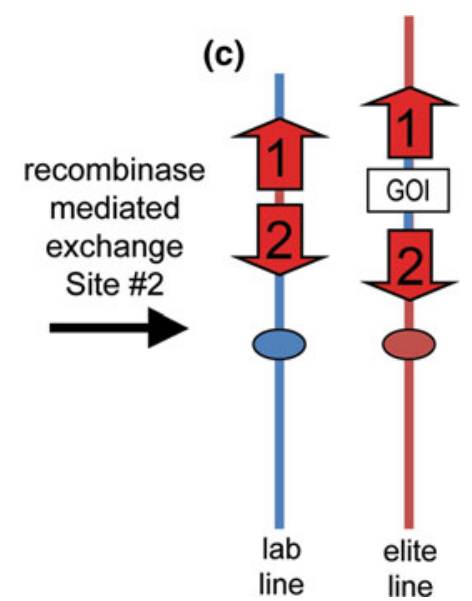

Fig. 5 Schematic representation of a recombinase-mediated introgression event. The gene of interest (GOI) is flanked by oppositely oriented recombinase recognition sites (red arrows; \#s 1 and 2). Inverted recognition sites prevent unwanted DNA excision. The recombination event targets the DNA between the associated recognition sites of different chromosomes. Two recombination events are needed to break the linkage drag associated with tradition

breeding techniques. a The first event produces a transposition between the different chromosomes of the lab and elite lines (see recognition sites; red arrows \# 1). b The second recombination event reverses the transposition (see recognition sites; red arrows \# 2) and c leaves the transgene in the elite line. In theory this technique could be used to stack genes directly from laboratory lines into elite lines 
$\sim 33 \%$ in tobacco (Albert et al. 1995; Day et al. 2000) to nearly 50\% in rice (Srivastava et al. 2004). In other words, a minimum of one plant in three demonstrated a precise single copy insertion event. Of the single copy insertion events reported in rice, nearly all displayed consistent expression patterns based on genomic loci, while in tobacco approximately half showed uniformity. The remaining half of the tobacco single copy transgene insertions were affected by methylation-dependent DNA silencing (Day et al. 2000). These rates are much better than $\sim 1-10 \%$ single copy insertion associated with random integration transformation methods. However, it should be pointed out that compared to conventional methods, the tissue culture process for transformation is labor intensive and time consuming due to the number of explants (protoplasts or callus) required. For practical purposes the transformation efficiency would need improvement. In another study, Chawla et al. (2006) documented that site-specific integration in rice exhibited stable gene expression over multiple generations. Also, noted in this study was how multi-copy transgenic plants initially silenced, recovered expression when segregation removed the extra transgene copies. This can most likely be attributed to inactivation of homology-dependent gene silencing due to removal of repetitive transgene DNA (Jakowitsch et al. 1999; Luff et al. 1999).

Targeted integration can be achieved by co-transforming a cell containing a single recombinase recognition site within the genome with two plasmids (Fig. 6). One plasmid contains the complimentary recognition site along with the gene of interest and the other contains the recombinase expression cassette. This was first shown with the Cre recombinase in yeast (Sauer and Henderson 1990), thereby demonstrating targeted site-specific insertion into a eukaryotic genome. Cre, Flp and R are reversible recombinase systems (RRS) that favor excision over integration, thus to facilitate integration, modifications were required. Improved targeted integration using Cre was achieved by providing the recombinase transiently thereby trapping the DNA in its final position as the enzyme expression ceased (Baubonis and Sauer 1993; Albert et al. 1995; Vergunst and Hooykaas 1998; Srivastava and Ow 2001). This strategy was improved upon by placing the initial target loxP recognition site in the genome between the promoter and open reading frame of the Cre recombinase. In this manner, the recombinase protein is pre-loaded within the cell allowing integration. Once integrated, the recombinase open reading frame is displaced from the promoter and effectively shut off thereby trapping the DNA in the integrated state. This technique has been very effective for the reversible recombination systems of Cre and Flp. It has been used for integration in Arabidopsis (Vergunst et al. 1998), tobacco (Albert et al. 1995; Choi et al. 2000; Day

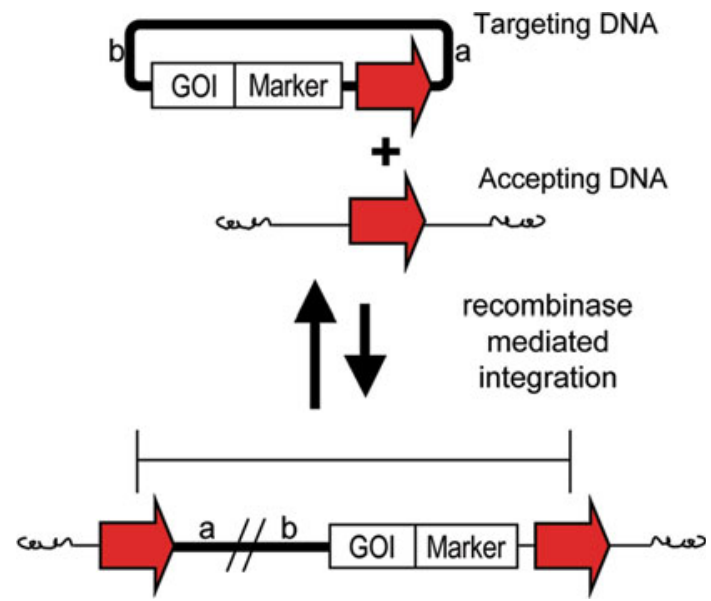

Fig. 6 Schematic representation of a recombinase-mediated integration event. The targeting DNA is circular and contains a single recognition site (red arrow), a selectable marker and gene of interest. The accepting DNA (in genome) contains a single complimentary recognition site. The resulting integration event between the two associated recognition sites inserts the entire circular targeting DNA fragment into the genome. For the reversible recombinases this leaves an unstable configuration of two directly oriented recognition sites that can be immediately excised. Transient expression of the reversible recombinase is commonly used to trap the integrated DNA-not shown

et al. 2000) and rice (Srivastava and Ow 2002; Srivastava et al. 2004; Chawla et al. 2006). A novel twist was employed that used two loxP sites in the targeting DNA, such that in the presence of Cre, all unwanted 'backbone/ vector' DNA was removed producing a circular fragment. The circular DNA was subsequently integrated into the genomic loxP site providing a 'clean' transgene (Kolb and Siddell 1997; Vergunst et al. 1998; Vergunst and Hooykaas 1998; Srivastava et al. 2004). Integration of plasmid backbone into the host genome has been linked to transgene silencing, and therefore its removal is desirable (Iglesias et al. 1997).

A model proposed by Hoess and Abremski (1984) suggested that mutations in one of the two $13 \mathrm{bp}$ binding domains of a $\operatorname{lox} P$ recognition site could be tolerated. By definition the RRSs Cre, Flp and $\mathrm{R}$ have recognition sites lox $P, F R T$ and $R S$ that contain two recombinase-binding domains separated by a spacer region that determines orientation of the sequence. When one $13 \mathrm{bp}$ binding domain was mutated cooperative Cre-Cre interaction allowed loxP site attachment to occur normally, but if mutations were in both $13 \mathrm{bp}$ binding domains overall binding efficiency dropped significantly. Mutant loxP sites could be tolerated for integration since each loxP site had one 'good' binding domain facilitating normal enzyme attachment. After recombination, one loxP site would be wild type, while the other would have a mutation in both its binding domains inhibiting further Cre attachment, thereby trapping the 


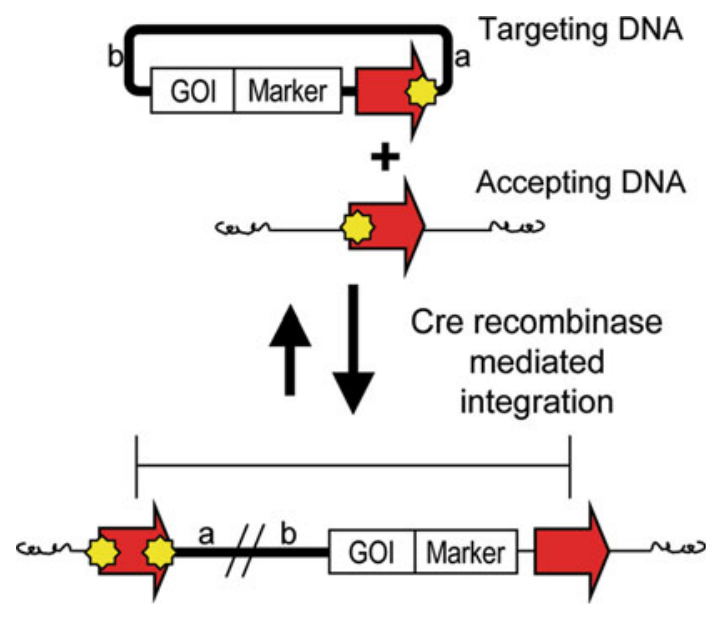

Fig. 7 Schematic of recombinase-mediate integration with mutant lox $P$ sites schematic. As the reversible recombinase Cre results in an unstable configuration upon integration, use of $\operatorname{lox} P$ recognition sites with half site mutations (red arrow with yellow star) have been exploited. The half site mutations allow integration to occur at approximately wild type rates due to cooperative binding of the recombinase to the recognition site. Once recombined and both half site mutation are brought together future recombination events (excision) are inhibited thereby trapping the integration event. This is believed to be due to the loss of cooperative binding. Transient expression of the reversible recombinase further enhances the effectiveness of trapping of the integrated DNA—not shown

DNA in the integrated position (Fig. 7). This prediction was demonstrated through the use of randomly generated mutant loxP sites (Albert et al. 1995). The system was tested in vitro with a plasmid inversion system so both forward and reverse reactions could be analyzed. These optimized mutant loxP sites have subsequently allowed targeted integration to be achieved at useful level in plants such as tobacco (Albert et al. 1995; Day et al. 2000), rice (Srivastava and Ow 2002; Srivastava et al. 2004; Chawla et al. 2006) and maize (Srivastava and Ow 2001). Use of double mutant recognition $F R T$ sites for enhanced integration stability with Flp system has not been successful, probably due to the intrinsic nature of the Flp/FRT interaction, where Flp binding is not a cooperative event (Senecoff et al. 1988; Huang et al. 1991).

Another option for chromosomal targeting involves the use of endogenous genome located recognition sites (or cryptic sites) provides an additional option for targeted chromosomal integration. This method has been demonstrated in various prokarotes and eukaryotes (Sauer and Henderson 1990; Sauer 1996; Thyagarajan et al. 2000, 2001; Groth et al. 2000; Olivares et al. 2001; Thomson et al. 2003; Allen and Weeks 2005, 2009; Held et al. 2005; Calos 2006; Ou et al. 2009). Research for plants has only been recently conducted identifying potential cryptic recognition sites via sequence analysis (Thomson et al. 2009, 2010). However, empirical studies are required to determine the utility of the predicted sites for practical application. Other researchers have used DNA mutagenesis techniques to modify the recombinase's binding domain to more effectively recognize the cryptic site with the genome of interest. The Calos lab has modified the phiC31 recombinase to more effectively bind a cryptic attP site from the human chromosome (Sclimenti et al. 2001; Keravala et al. 2009). The modified phiC31 has shown enhanced genome targeting capacity and gene delivery (Keravala et al. 2009; Chavez et al. 2010). The use of recombinase in the field of gene therapy has provided a substantial step forward for programmed genetic treatment of incurable diseases.

Despite the potential advantages, the commercial application of recombinase-mediated technology in plants has been modest. This is due, in part, to the intellectual property restrictions that limit the availability and commercial use of the effective recombination systems Cre, Flp and R. To provide DNA manipulation tools for genetic modification with the freedom to operate, a number of labs have recently screened and described novel recombinase systems with properties analogous to the irreversible recombination system (IRS) phiC31 (Thorpe and Smith 1998; Thomason et al. 2001). These systems are from the large serine subfamily, which perform recombination between non-identical attB and $a t t P$ recognition sites. As such, novel recombinase systems R4 (Olivares et al. 2001), TP901-1 (Stoll et al. 2002; Thomson and Ow 2006) and Bxb1 (Keravala et al. 2006; Russell et al. 2006; Thomson and Ow 2006) have been identified. These unidirectional recombinases present a unique set of tools for genomic engineering and offer improved techniques over those involving the RRS Cre, Flp or R recombinases. While effective, the bidirectional systems require more complex schemes in order to reduce the reverse reaction and trap the desired product—as previously described. In the $S$. pombe system described by Thomson and Ow (2006), the relative rates of completion for genomic integration of Bxb1, phiC31 and TP901-1 were 85, 95 and 78\%, respectively. These rates can be directly compared, since the unique target site for each respective recombinase was placed, by homologous recombination in the same genomic location, thereby removing positional effects.

The phiC31 recombinase system was the first large serine recombinase found to be functional in eukaryotes and the best characterized as a genomic engineering tool. PhiC31 has been tested in both Arabidopsis and wheat for its ability to excise a DNA fragment from the genome and transmit the excision event to next generation (Kempe et al. 2010; Thomson et al. 2010). These studies found that phiC31 was fully functional in the germinal tissue, which demonstrates that the recombination system is suitable for the generation of stable marker-free, recombinase-free transgenic plants. This recombinase has also been used for 
both integration (Lutz et al. 2004) and excision (Kittiwongwattana et al. 2007) within the tobacco plastid genome. The results showed that a transformation efficiency of 17 independent lines per bombarded sample was achieved via site-specific integration with long-term stable transgene expression observed. Most recently, Yau et al. (2010) describes the use of the Bxb1 large serine recombinase for site-specific integration into a pre-determined locus of the tobacco genome. In this experiment, a construct with the Bxb1 attP site was transformed into the tobacco genome (inserted via random integration). Single copy transgenic plants were isolated and used for site-specific integration of a plasmid containing the Bxb1 attB site and a hygromycinresistance gene. The Bxb1 recombinase-expressing plasmid was provided in trans and co-transformed into the protoplasts derived from the target lines by PEG-mediated transformation. Integration lines were obtained through hygromycin selection and confirmed with sequenced integration junction PCR products and Southern blot analysis. The primary results showed that approximately $5 \%$ of the transformation events were site-specific. For more details on the use of site-specific integration for crop plant improvement, see Srivastava and Gidoni (2010).

\section{Strategies combining recombinase-mediated integration and excision}

As a substantial number of site-specific recombination systems from prokaryotes and lower eukaryotes have been identified, future GM plants may be produced using multiple recombination systems and strategies for multi-gene stacking and deletion. Ow (2005) described a strategy for gene stacking and deletion using both a reversible and an irreversible recombination system. The idea rests on a concept that the integrating DNA carries an extra recombination site, such that after insertion into the plant genome, the extra recombination site becomes a new target for the next round of DNA integration (Fig. 8). However, this strategy as described can only apply to sexually propagated plants due to crossing requirements. For each round of targeted integration, the target plant line has to be crossed with the recombinase expression line in order to remove the marker gene, with a second generation being required for segregation to remove the recombinase gene. Although time consuming, this technique is powerful allowing multiple genes (or groups of genes) to be sequentially stacked into a predetermined genomic locus.

An alternative to the previously described strategy would be the inclusion of an inducible recombinase system for excision without crossing and segregation of the recombinase gene as currently proposed (Fig. 8). There are several advantages to this revised strategy. First, only one selectable marker gene is used for both target construct and stacking vector. Second, the strategy avoids the need for crossing and segregation of a recombinase gene to mediate excision as both the marker and recombinase gene are deleted once recombinase expression is induced. Third, only two simple vectors are used. Theoretically, this strategy could be used to stack numerous genes in one transgenic plant line via irreversible site-specific recombination utilizing $a t t B$ and $a t t P$ recognition sites. Finally, the overall strategy could benefit greatly by the use of a positive/negative selectable marker cassette to allow direct selection of plants that have undergone an excision event (Kondrak et al. 2006). Negative selection prior to molecular characterization would save time and effort invested in screening for candidate lines (Gleave et al. 1999).

\section{Recombinase-mediated cassette exchange (RMCE)}

A unique targeted integration strategy was developed that takes advantage of the homology requirement between the 8 bp-spacer region of recombining FRT, loxP and $R S$ sites (Hoess et al. 1986; Lee and Saito 1998; Nanto et al. 2005). This technique is termed recombination-mediated cassette exchange and was originally used with the Flp/FRT recombinase system (Schlake and Bode 1994; Seibler and Bode 1997; Seibler et al. 1998). This technique has been shown to be an efficient way to produce transgenics with a minimum of excess DNA added to the host (Bouhassira et al. 1997). This strategy combines both site-specific integration and excision mediated by one recombinase. The approach involves a targeted integration event followed by a recombinase-mediated excision event removing unwanted transgenic DNA (Fig. 9). The initial design is similar to most biphasic systems where a tagged genome (TAG) must first be generated before it can be further modified by the recombinase. The 'TAG' usually consists of a positive selectable marker flanked by two inverted recognition sites. The inverted recognition site orientation inhibits unwanted 'TAG' auto-excision. The 'EXCH' plasmid also contains inverted recognition sites and flanks the DNA of interest to be inserted into the genome. These recognition sites are homologous to the sites already within the genome. The recombinase gene is either provided in cis on the incoming DNA, outside the flanked 'EXCH' cassette, or in trans from a separate molecule. Re-transformation of the 'TAG' lines with the recombinase and exchange $(\mathrm{EXCH})$ vector allows a double recombination event to swap DNA. During the double recombinase-mediated exchange event, both sets of homologous sites will undergo a separate recombination event exchanging the original 'TAG' gene with the incoming 'EXCH' gene. This is predicted to be a two-step process where one site initially undergoes recombination 
(a) GO11 attB lox rew Pre-existing genomic 'TAG'

(b)

Incoming vector

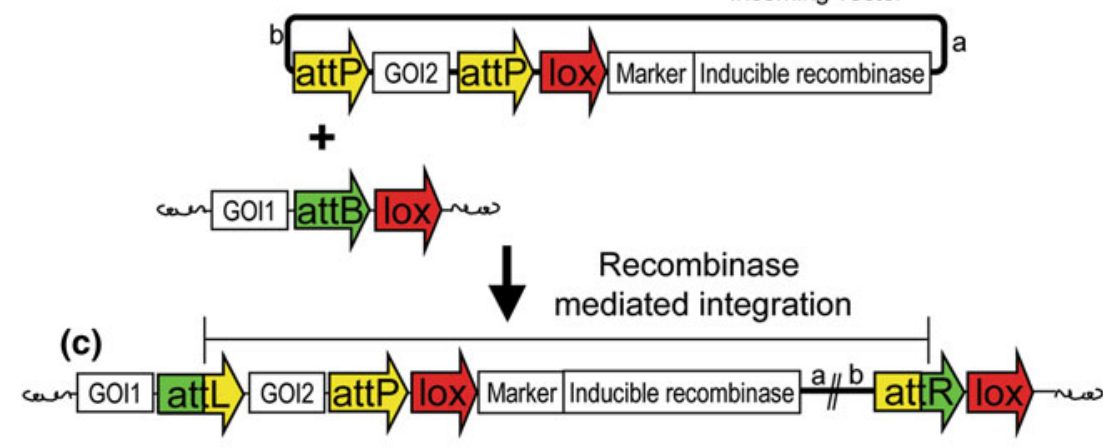

(d)

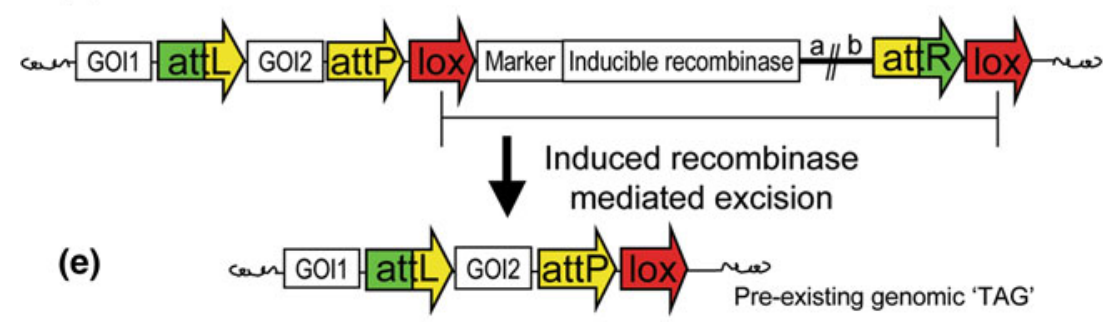

(f)
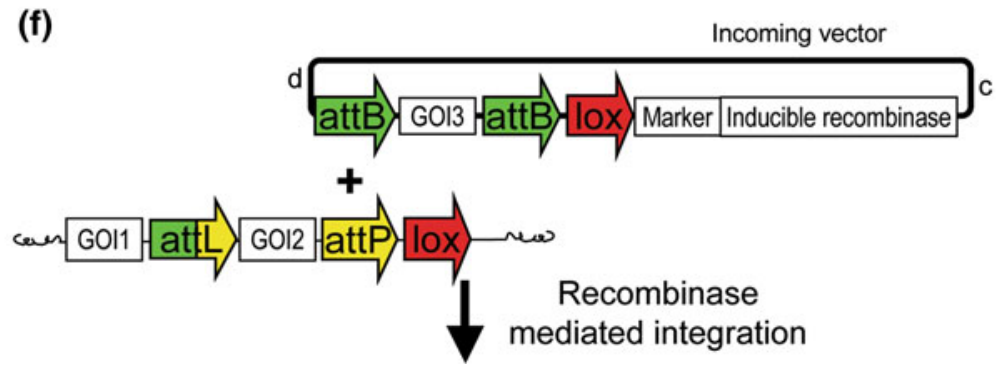

Fig. 8 The schematic representation of gene stacking via recombinase technology. a The original 'TAG' DNA contains a previously targeted gene of interest 1 (GOI1), an IRS recognition site (attB, green arrow) and an RRS recognition site (lox, red arrow). b For effective gene stacking an incoming vector consisting of an attPGOI2-attP-lox-Marker-inducible Cre can be introduced into the 'TAG' line (attP, yellow arrow is the complimentary IRS recognition site for $a t t B$ ). The IRR recombinase is provided transiently by a cotransformed plasmid. c Recombination between $a t t B$ and one of the two $a t t P$ sites integrates GOI2 construct into the GOI1 locus. As two attP sites are present on the incoming vector integration will produce

integrating the entire construct into the genome followed by a second recombination event removing the 'TAG' gene (selectable marker) from the genome along with the 'EXCH' plasmid backbone, leaving behind the 'exchanged' DNA of interest (Fiering et al. 1993; Feng et al. 1999; Thomason et al. 2001; Nanto et al. 2005). Recent evidence through the use of an atomic force microscope has confirmed that RMCE is a two-step process (Malchin et al. a useful product only $50 \%$ on the time. d Induction of Cre will remove both itself and the marker gene, leaving the e GOI1-attLGOI2-attP-lox structure (attL and attR, bicolouerd yellow/green arrows are the hybrid sites of the attB/attP integration and are not competent for further recombination). The remaining genome located attP is available for future targeted integration at the 'TAG' locus. f Analogous to the previous steps, the attP can be used to add a third gene, GOI3, with the construct attB-GOI3-attB-lox-Marker-inducible $C r e$ and bring in a new $a t t B$ site for yet another round of integration. Not all possible conformations are represented

2008). Because the Cre recombinase is more active than Flp (Buchholz et al. 1996; Dymecki 1996; Westerman and Leboulch 1996), the RMCE system was redesigned to include the $\operatorname{lox} P$ site. It was modified yet again to accommodate the use of other recombinase systems.

A limitation to the use of the bidirectional tyrosine recombinases (Cre, $\mathrm{R}$ or Flp) is the reversible nature of the recombination events, meaning that the RMCE can be 


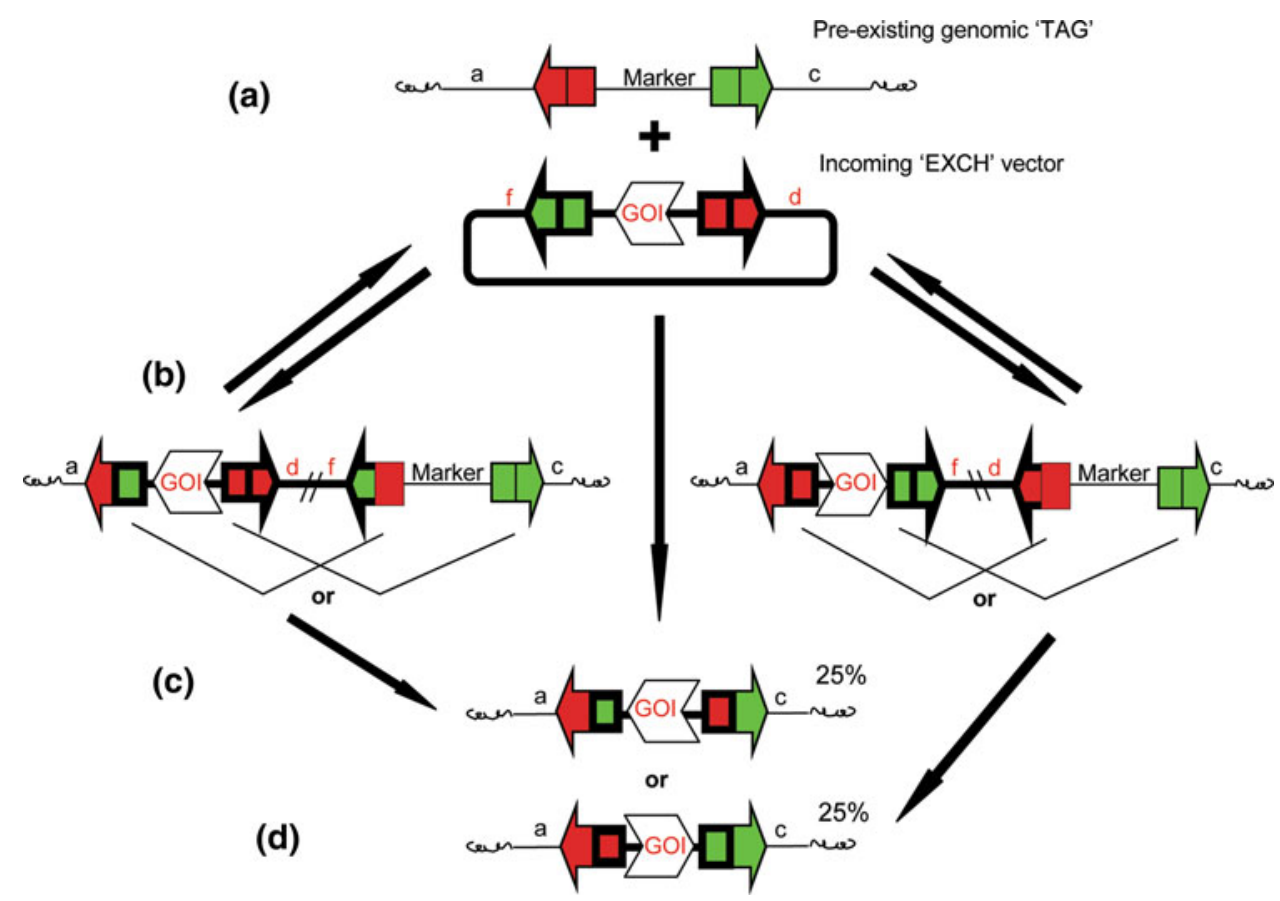

Fig. 9 General RMCE schematic for a single bidirectional recombinase (the green and red arrows represent identical recognition sites and colors are only intended to allow visualizing of the various recombination possibilities). This technique has been shown to be an efficient way to produce transgenics with a minimum of excess DNA added to the host. This strategy combines both site-specific integration and excision mediated by one recombinase. The approach involves a targeted integration event followed by a recombinasemediated excision event removing the unwanted transgenic DNA. Specifically, RMCE is a technique where DNA can be integrated in a specific manner to a pre-existing genomic target 'TAG' with a minimum of backbone DNA. The pre-existing 'TAG' contains a selectable marker (Marker) and is flanked by inverted RRS recognition sites (red and green arrows, thin lines). The incoming plasmid

reversed at any step in the process or even be repeated. Further, the final product can be integrated in two possible orientations making molecular confirmation complex. However, despite these potential limitations, this technique has been used to successfully generate transgenic yeast, mammalian cells, mice, Drosophila and plants (Feng et al. 1999; Baszczynski et al. 2003; Belteki et al. 2003; Horn and Handler 2005; Nanto et al. 2005; Louwerse et al. 2007; Nanto and Ebinuma 2008; Watson et al. 2008; Li et al. 2009; Nanto et al. 2009; Fladung and Becker 2010). Scientists working in mammalian systems have demonstrated targeting efficiencies approaching $100 \%$, from a preexisting chromosomal site, through the use of a negativeselection marker exchange vector. They have reported that the technique is powerful enough to specifically integrate into a targeted location without the use of any selection and still obtain an integration frequency of $1 \%$ (Feng et al. 1999). Recombinase systems that have been successful with this method include Cre/loxP, Flp/FRT, R/RS, phiC31
DNA contains a gene of interest (GOI) also flanked by inverted RRS recognition sites (red and green arrows, thick lines) and is termed the exchange 'EXCH' cassette. The recombinase will integrate the incoming 'EXCH' DNA into the 'TAG' utilizing one of the two flanking recognition sites. To proceed forward, the second set of recognition sites are then used for site-specific excision of the intervening DNA. This results in the switch the GOI of the ' $\mathrm{EXCH}$ ' cassette for the (Marker) of the 'TAG' DNA. Although useful, inverted sites also result in 'exchanged' cassettes with both forward and reverse orientations making the molecular conformation more complicated and differing transgene expression levels. Not all possible conformations are represented. The recombinase can be provided in cis or in trans-not shown

and $\mathrm{Bxb} 1$, indicating that even bidirectional recombinases such as Flp and R, which are reported to be less active than $\mathrm{Cre}$, can be successfully used in this strategy. Of interest is the fact that this technique has been successfully employed using both direct DNA transformation and Agrobacteriummediated methods (Vergunst et al. 1998; Nanto and Ebinuma 2008).

Use of the reversible recombinase systems Cre/loxP, $\mathrm{Flp} / F R T$ and $\mathrm{R} / R S$ require special attention due to unwanted self-excision. Careful cloning strategies must be devised to avoid generating directly oriented recombinasebinding sites on the same construct, which can result in premature excision (Nanto et al. 2005; Louwerse et al. 2007; Nanto and Ebinuma 2008). Use of heterologous or mutant binding sites has been shown to reduce this problem with some success (Louwerse et al. 2007; Watson et al. 2008). Unfortunately, minor differences in heterologous binding sites are not always sufficient to inhibit unintended DNA excision (Siegel et al. 2001). While mutant binding 
sites help stabilize the integration event of a reversible recombinase system, recombination efficiency is lowered which correlates with the stabilizing effect of specific mutations (Albert et al. 1995; Thomson et al. 2003; Araki et al. 2010). Also, some recombinase systems such as $\mathrm{R} / R S$ do not have known mutant sites. As mentioned earlier, the most universally successful binding site strategy employs a design where the orientation of the recombination sites is in an inverted arrangement for both the 'TAG' and ' $\mathrm{EXCH}$ ' constructs. Although useful, inverted sites also result in 'exchanged' cassettes with both forward and reverse orientations resulting in differences in transgene expression levels (Fig. 9) (Feng et al. 1999; Nanto et al. 2005, 2009).

A modification to RMCE is a strategy that employs two recombinase expression systems where both recombinase enzymes are simultaneously expressed. Lauth et al. (2002) first demonstrated the use of the Cre/loxP and FLP/FRT systems, along with the use of mutant binding sites to stabilize the integration event. Targeting without selection was $3 \%$. Put into perspective, this is $3 \mathrm{X}$ better than the levels obtained with homologous recombination using a selectable marker. The research did, however, require the use of a flow-assisted cell sorter (or FACS) to isolate transgenic tissue culture cells and failed to address the presence or absence of the recombinase genes in the final cell lines. Two other groups have now used a modified dual RMCE technique. Dafhnis-Calas et al. (2005) used the Cre/ loxP and phiC31 recombinases for RMCE. The authors called their technique 'iterative site-specific integration' and used it in mammalian cell culture to stack genes into the same locus. However, this strategy required the retention of a selectable marker in the resultant transformed lines, while a publication by Nanto and Ebinuma (2008) demonstrated the use of both $\mathrm{R} / R S$ and Cre/loxP systems for RMCE in tobacco. This well executed study successfully generated marker-free single copy targeted integration transgenic lines. Agrobacterium was used as the vehicle for transformation demonstrating that RMCE can be executed from the incoming T-DNA molecule. Further, the R/RS RMCE targeting strategy (Nanto et al. 2005; Nanto and Ebinuma 2008) was enriched for 'clean' exchange events by including an extra RS recognition site within the incoming vector. If random integration were to occur, the continued expression of the $\mathrm{R}$ recombinase gene would excise the incoming vector removing the entire construct from the genome, minus an LB- $R S$-RB footprint.

We describe here a novel approach to RMCE that can potentially overcome the limitations previously described. This strategy utilizes two unidirectional recombinase systems and was developed to create single insertion events in previously characterized lines having stable expression patterns. The system is intended for high throughput gene integration such as those needed by biopharmaceutical companies for protein production or for the study of genes with regard to biotechnology risk assessment. Another important feature is that the insertion event itself is unidirectional, and thus transgene expression will be constant and not compromised by forward and reverse insertion directions, unlike most RRS-dependent RMCE techniques. The large serine recombinases, namely Bxb1 and phiC31, are naturally unidirectional, and therefore trap the DNA within their target loci. The second recombinase needed for excision is an irreversible small serine recombinase. Due to topological constraints (Sarkis et al. 2001; Mouw et al. 2008), these recombinases are only capable of site-specific excision and therefore cannot re-integrate DNA into the genome, as can occur with bidirectional tyrosine systems (Srivastava and Ow 2003). During this process the selectable marker, recombinase genes and plasmid backbone will be eliminated from the host genome during the initial transformation event (Fig. 10). All progenies containing the gene of interest produced and confirmed from the initial transformation will serve as the final product. In other words the plant lines will be immediately available for production and/or study. No secondary crosses or segregation to remove unwanted DNA is necessary. This design employs a positive/negative selectable marker scheme that has been very effective for replacement strategies (Kondrak et al. 2006; Nanto and Ebinuma 2008) and makes the site-specific excision event completely dependent on precise integration and cell survival. When the 'EXCH' vector is site-specifically inserted into the chromosomal 'TAG' cassette, the recognition sites required for excision will align stimulating the removal of the positive/negative selectable marker gene (Fig. 10). This technique is meant to eliminate undesirable random genomic integration, thereby reducing background and screening time. The presence of the negative marker gene (e.g. $\operatorname{cod} A)$ eliminates cells that experienced site-specific integration of the 'EXCH' cassette without subsequent excision, and those cells that had only random integration events.

This strategy can be modified for gene stacking by including a second, integration-specific recognition site into the 'EXCH' vector. This design results in an additional recognition site being added to the insertion locus, and can be used as subsequent target site. By placing the additional site in an inverted orientation only the correctly targeted recognition site will allow negative marker gene, $\operatorname{cod} A$, to be excised and thus selection of the appropriate event.

\section{Conclusion}

This review summarizes the impact that site-specific recombination-based technologies are having on the field of genomic engineering, and how these methods will 
Pre-existing genomic 'TAG'

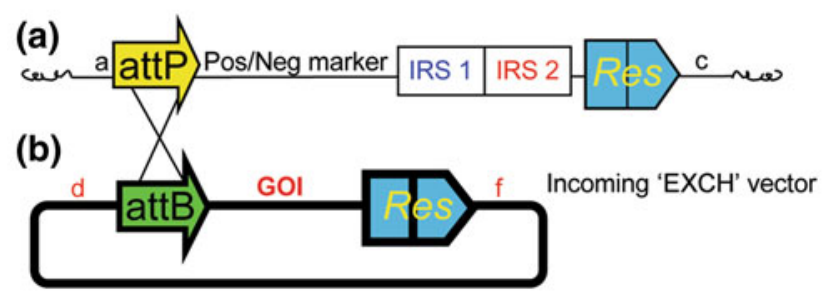

(c) IRS 1 recombinase mediated

(c)
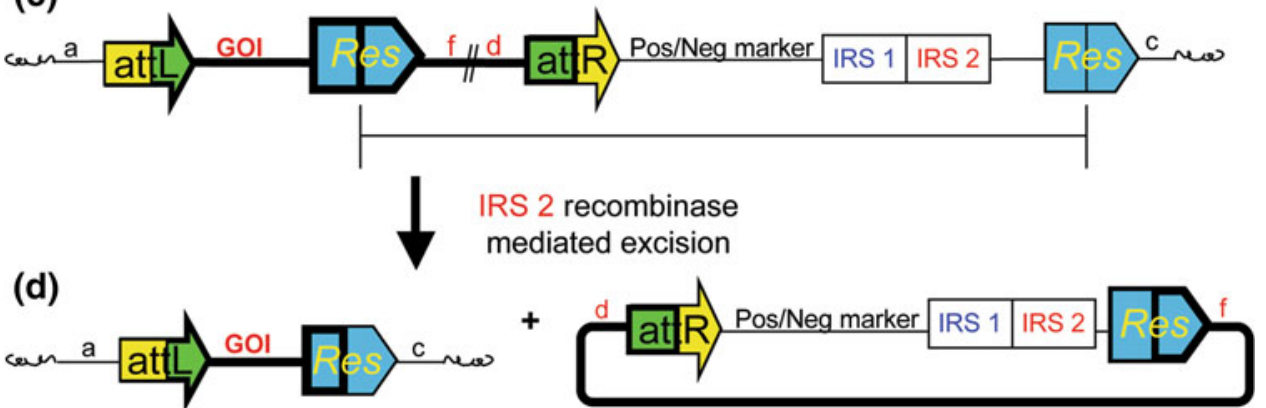

Fig. 10 Schematic representation of the irreversible recombinasemediated cassette exchange. This strategy simultaneously uses two irreversible recombinases, one for integration into the pre-existing chromosomal 'TAG,' and one for excision of unwanted DNA. This strategy traps the GOI from the incoming ' $\mathrm{EXCH}$ ' cassette in the genome (seen as circle with thick lines). Even though two recombinase-mediated events are necessary, these reactions occur in a single transformation experiment. Integration of the 'EXCH' cassette is identified via negative selection against the presence of the Pos/Neg selectable marker. The design makes the proper alignment of the recognition sites for excision dependent on the site-specific integration event. No site-specific or random integration event where the negative selection marker is present survives negative selection. a The 'TAG' contains a positive-negative selectable marker and two irreversible recombinase genes flanked by the recognition sites (attP and Res) of both IRR systems, represented by yellow and blue arrows, respectively. b The 'EXCH' vector is a simple vector containing a

change genomic engineering in the future. This technology enables the removal of extraneous DNA such as selectable markers, (i.e. antibiotic resistance genes) from the genome as well as speeds the transition from laboratory manipulation to field production; an important benefit for both the industry and general public. From an application point of view, the number and type of recombinases available along with the innovative strategies being developed offer a multitude of applications for genome manipulation; with everything from single copy high throughput targeted integration, to sequential gene stacking, to complete transgene removal from the pollen and/or seed. These strategies are applicable to the commonly used transformation methods of biolistics and Agrobacterium providing the widest available use in diverse systems. Site-specific recombinase technology is ready for routine application of
GOI flanked by the recognition sites of the two corresponding IRR systems (attB and Res, represented by green and blue arrows, respectively. c Irreversible recombinase-mediated integration inserts the entire plasmid into the pre-existing 'TAG' loci (i.e. the yellow and green arrows are recombined-integration). Site-specific integration aligns the Res recognition sites in direct orientation (blue arrows) enabling excision. Irreversible recombinase-mediated excision removes the positive-negative marker and recombinase genes from the genome (i.e. the Res sites are recombined-excising the undesirable DNA). d Upon completion of both irreversible recombination events, the GOI has been site-specifically inserted into the genome free of unwanted plasmid backbone, marker and recombinase genes. Circularized DNA does not replicate and cannot be reintegrated into the genome via the recombinase genes as neither the att $L$, attR (seen as bicolored yellow and green arrows) or Res recognition sites (blue arrows) can mediate genomic integration

genomic engineering and will likely become an integral part of crop biotechnology, enabling the technology to generate improved crops that rely less on pesticides and fertilizers and have the ability to produce high quality, abundant foods impacting the farm economy. However, utilization of recombinases as tools for genome manipulation has seen limited use. This could be due to the perceived complexity of the systems involved (Albert et al. 1995) or possibly to the low efficiencies observed in initial recombinase studies (Vergunst and Hooykaas 1998; Vergunst et al. 1998). However, through improvement to initial protocols practical utilization of recombinase technology has been demonstrated (Srivastava and Ow 2002; Baszczynski et al. 2003; Srivastava et al. 2004; Nanto et al. 2005; Louwerse et al. 2007; Nanto and Ebinuma 2008; Li et al. 2010). In addition, the RMCE strategy and general 
availability of recombinases provide greater commercial application to the use of these systems. The public will further benefit from a greater supply of healthy, economical foods, and issues of hunger facing economically challenged regions of the world can be more easily addressed. Finally, public and regulatory concerns over the potential unintended effects of extraneous DNA may also be alleviated, improving acceptance for genetically engineered crops in the future.

Acknowledgments We are grateful to R. Thilmony for critical reading of the manuscript. Research was funded by USDA-ARS project 5325-21000-002-00D.

Open Access This article is distributed under the terms of the Creative Commons Attribution Noncommercial License which permits any noncommercial use, distribution, and reproduction in any medium, provided the original author(s) and source are credited.

\section{References}

Afolade AS (2007) Status of clean gene (selection marker-free) technology. Afr J Biotechnol 6(25):2910-2923

Albert H, Dale EC, Lee E, Ow DW (1995) Site-specific integration of DNA into wild-type and mutant lox sites placed in the plant genome. Plant J 7:649-659

Allen BG, Weeks DL (2005) Transgenic Xenopus laevis embryos can be generated using phiC31 integrase. Nat Methods 2:975-979

Allen BG, Weeks DL (2009) Bacteriophage phiC31 integrase mediated transgenesis in Xenopus laevis for protein expression at endogenous levels. Methods Mol Biol 518:113-122

Araki K, Araki M, Miyazaki J, Vassalli P (1995) Site specific recombination of a transgene in fertilized eggs by transient expression of Cre recombinase. Proc Natl Acad Sci 92:160-164

Araki K, Okada Y, Araki M, Yamamura KI (2010) Comparative analysis of right element mutant lox sites on recombination efficiency in embryonic stem cells. BMC Biotechnol 10:29. doi: 10.1186/1472-6750-10-29

Ballester A, Cervera M, Pena L (2006) Efficient production of transgenic citrus plants using isopentenyl transferase positive selection and removal of the marker gene by site-specific recombination. Plant Cell Rep 26:39-45

Baszczynski CL, Gordon-Kamm WJ, Lyznik LA, Peterson DJ, Zhao ZY (2003) Site-specific recombinases and their uses for targeted gene manipulation in plant systems. In: Stewart CN Jr (ed) Transgenic plants: current innovations and future trends. Horizon, Wymondham, pp 157-178

Baubonis W, Sauer B (1993) Genomic targeting with purified Cre recombinase. Nucl Acids Res 9:2025-2029

Belteki G, Gertsenstein M, Ow DW, Nagy A (2003) Site-specific cassette exchange and germline transmission with mouse ES cells expressing phiC31 integrase. Nat Biotechnol 21:321-324

Bevan MW, Flavell RB, Chilton MD (1983) A chimeric antibiotic resistance gene as a selectable marker for plant cell transformation. Nature 304:184-187

Bouhassira EE, Westerman K, Leboulch P (1997) Transcriptional behavior of LCR enhancer elements integrated at the same chromosomal locus by recombinase-mediated cassette exchange. Blood 90:3332-3344

Brocard J, Feil R, Chambon P, Metzger D (1998) A chimeric Cre recombinase inducible by synthetic, but not by natural ligands of the glucocorticoid receptor. Nucleic Acids Res 26(17):40864090

Brookes G, Barfoot P (2009) Global impact of biotech crops: income and production effects, 1996-2007. AgBioForum 12(2):184208

Buchholz F, Ringrose L, Angrand P, Rossi F, Stewart FA (1996) Different thermostabilities of FLP and Cre recombinases: implications for applied site-specific recombination. Nucl Acid Res 24:4256-4262

Burdon TG, Wall RJ (1992) Fate of microinjected genes in preimplantation mouse embryos. Mol Reprod Dev 33:436-442

Burgess SM, Kleckner N (1999) Collisions between yeast chromosomal loci in vivo are governed by three layers of organization. Genes Dev 13:1871-1883

Calos MP (2006) The phiC31 integrase system for gene therapy. Curr Gene Ther 6:633-645

Cao MX, Huang JQ, Yao QH, Liu SJ, Wang CL, Wei ZM (2006) Site-specific DNA excision in transgenic rice with a cellpermeable Cre recombinase. Mol Biotechnol 32:55-63

Chavez CL, Keravala A, Woodard LE, Hillman RT, Stowe TR, Chu JN, Calos MP (2010) Human gene therapy kinetics and longevity of C31 integrase in mouse liver and cultured cells. PloS One. doi:10.1089/hum.2010.049)

Chawla R, Ariza-Nieto M, Wilson AJ, Moore SK, Srivastava V (2006) Transgene expression produced by biolistic-mediated, site-specific gene integration is consistently inherited by the subsequent generations. Plant Biotechnol J 4:209-218

Chen KS, Manian P, Koeuth T, Potocki L, Zhao Q, Chinault AC, Lee CC, Lupski JR (1997) Homologous recombination of a flanking repeat gene cluster is a mechanism for a common contiguous gene deletion syndrome. Nat Genet 17:154-163

Choi S, Begum D, Koshinsky H, Ow DW, Wing RA (2000) A new approach for the identification and cloning of genes: the pBACwich system using Cre/lox site-specific recombination. Nucl Acids Res 28:E19

Christ N, Droge P (2002) Genetic manipulation of mouse embryonic stem cells by mutant lambda integrase. Genesis 32:203-208

Clark AJ, Bissinger P, Bullock DW, Damak S, Wallace R, Whitelaw CBA, Yull F (1994) Chromosomal positional effects and the modulation of transgene expression. Reprod Fertil Dev 6:589-598

Collick A, Drew J, Penberth J, Bois P, Luckett J, Scaerou F, Jeffreys A, Reik W (1996) Instability of long inverted repeats within mouse transgenes. EMBO J 15:1163-1171

Comprehensive Reviews in Food Science and Food Safety (2008) In: Maize with increased lysine (lysine maize-LY038), vol 7, no. 1, Chap 6. Blackwell, USA, pp 99-106. ISSN 1541-4337

Cuellar W, Gaudin A, Solorzano D, Casas A, Nopo L, Chudalayandi P, Medrano G, Kreuze J, Ghislain M (2006) Self-excision of the antibiotic resistance gene nptII using a heat inducible Cre-loxP system from transgenic potato. Plant Mol Biol 62:71-82

Dafhnis-Calas F, Xu Z, Haines S, Malla SK, Smith MC, Brown WR (2005) Iterative in vivo assembly of large and complex transgenes by combining the activities of phiC31 integrase and Cre recombinase. Nucl Acids Res 33:e189

Dale EC, Ow DW (1991) Gene transfer with subsequent removal of the selection gene from the host genome. Proc Natl Acad Sci USA 88:10558-10562

Danielian PS, Muccino D, Rowitch DH, Michael SK, McMahon AP (1998) Modification of gene activity in mouse embryos in utero by a tamoxifen-inducible form of Cre recombinase. Curr Biol 8(24):1323-1326

Day CD, Lee E, Kobayashi J, Holappa LD, Albert H, Ow DW (2000) Transgene integration into the same chromosome location can produce alleles that express at a predictable level, or alleles that are differentially silenced. Genes Dev 14:2869-2880 
De Wit T, Drabek D, Grosveld F (1998) Microinjection of Cre recombinase RNA induces site-specific recombination of a transgene in mouse oocytes. Nucl Acids Res 26:676-678

Deursoen JV, Fronerod M, Rees BV, Grosveld G (1995) Cremediated site-specific translocation between nonhomologous mouse chromosomes. Proc Natl Acad Sci USA 92:7376-7380

Diaz V, Servert P, Prieto I, Gonzalez MA, Martinez AC, Alonso JC, Bernad A (2001) New insights into host factor requirements for prokaryotic beta-recombinase-mediated reactions in mammalian cells. J Biol Chem 276:16257-16264

Djukanovic V, Lenderts B, Bidney D, Lyznik LA (2008) A Cre:FLP fusion protein recombines FRT or loxP sites in transgenic maize plants. Plant Biotechnol J 6:770-781

Dobie K, Mehtali M, McClenaghan M, Lathe R (1997) Variegated gene expression in mice. TIG 13:127-130

Dymecki SM (1996) Flp recombinase promotes site-specific DNA recombination in embryonic stem cells and transgenic mice. Proc Natl Acad Sci USA 93:6191-6196

Ebinuma H, Komamine A (2001) MAT (multi-auto-transformation) vector system. The oncogenes of Agrobacterium as positive markers for regeneration and selection of marker-free transgenic plants. In Vitro Cell Dev Biol 37:103-113

Endo S, Kasahara T, Sugita K, Matsunaga E, Ebinuma H (2001) The isopentenyl transferase gene is effective as a selectable marker gene for plant transformation in tobacco (Nicotiana tabacum $\mathrm{cv}$. Petite Havana SR1). Plant Cell Rep 20:60-66

Endo S, Sugita K, Sakai M, Tanaka H, Ebinuma H (2002) Single-step transformation for generating marker-free transgenic rice using the ipt-type MAT vector system. Plant J 30:115-122

Feil R, Brocard J, Mascrez B, LeMeur M, Metzger D, Chambon P (1996) Ligand-activated site-specific recombination in mice. Proc Natl Acad Sci USA 93(20):10887-10890

Feng YQ, Seibler J, Alami R, Eisen A, Westerman KA, Fiering S, Bouhassira EE (1999) Site-specific chromosomal integration in mammalian cells: highly efficient Cre recombinase-mediated cassette exchange. J Mol Biol 292:779-785

Fiering S, Kim CG, Epner EM, Groudine M (1993) An "in-out" strategy using gene targeting and FLP recombinase for the functional dissection of complex DNA regulatory elements: analysis of the beta-globin locus control region. Proc Natl Acad Sci USA 90:8469-8473

Fladung M, Becker D (2010) Targeted integration and removal of transgenes in hybrid aspen (Populus tremula $\mathrm{L} . \times$ P. tremuloides Michx.) using site-specific recombination systems. Plant Biol 12:334-340

Fraley RT, Rogers SG, Horsch RB, Sanders PR, Flick JS, Adams SP, Bittner ML, Brand LA, Fink CL (1983) Expression of bacterial genes in plant cells. Proc Natl Acad Sci USA 80:4803-4807

Gerlitz M, Hrabak O, Schwab H (1990) Partitioning of broad-hostrange plasmid RP4 is a complex system involving site-specific recombination. J Bacteriol 172:6194-6203

Ghosh P, Wasil LR, Hatfull GF (2006) Control of phage Bxb1 excision by a novel recombination directionality factor. PLoS Biol 4(6):e186. doi:10.1371/journal.pbio.0040186

Gidoni D, Srivastava V, Carmi N (2008) Site-specific excisional recombination strategies for elimination of undesirable transgenes from crop plants. In Vitro Cell Dev Biol Plant 44:457-467

Gilbertson L, Dioh W, Addae P, Ekena J, Keithly G, Neuman M, Peschke V, Petersen M, Samuelson C, Subbarao S, Wei L, Zhang W, Barton K (2003) Cre/lox mediated marker gene excision in transgenic crop plants. In: Plant Biotechnology and Beyond. Kluwer, Dordrecht, pp 225-228

Gleave AP, Mitra DS, Mudge SR, Morris BAM (1999) Selectable marker-free transgenic plants without sexual crossing: transient expression of cre recombinase and use of a conditional lethal dominant gene. Plant Mol Biol 40:223-235
Golic KG, Lindquist S (1989) The FLP recombinase of yeast catalyzes site-specific recombination in the Drosophila genome. Cell 59:499-509

Gottfried P, Lotan O, Kolot M, Maslenin L, Bendov R et al (2005) Sitespecific recombination in Arabidopsis plants promoted by integrase protein of coliphage HK022. Plant Mol Biol 57:435-444

Grindley ND, Whiteson KL, Rice PA (2006) Mechanisms of site specific recombination. Annu Rev Biochem 75:567-605

Groth AC, Olivares EC, Thyagarajan B, Calos MP (2000) A phage integrase directs efficient site-specific integration in human cells. Proc Natl Acad Sci USA 97(11):5995-6000

Halpin C (2005) Gene stacking in transgenic plants- the challenge for 21st century plant biotechnology. Plant Biotechnol J 3:141-155

Hare PD, Chua NH (2002) Excision of selectable marker genes from transgenic plants. Nat Biotechnol 20:575-580

Held PK, Olivares EC, Aguilar CP, Finegold M, Calos MP, Grompe $M$ (2005) In vivo correction of murine hereditary tyrosinemia type I by phiC31 integrase-mediated gene delivery. Mol Ther 11(3):399-408

Henikoff S (1998) Conspiracy of silence amoung repeated transgenes. BioEssays 20:532-535

Herault Y, Rassoultzdegun M, Cuzin F, Duboule D (1998) Engineering chromosomes in mice through targeted meiotic recombinase. Nat Genet 20:381-384

Herrera-Estrella L, Depicker A, van Montagu M, Schell J (1983) Expression of chimaeric genes transferred into plant cells using a Ti-plasmid-derived vector. Nature 303:209-213

Hoa TT, Bong BB, Huq E, Hodges TK (2002) Cre/lox site-specific recombination controls the excision of a transgene from the rice genome. Theor Appl Genet 104:518-525

Hoess RH, Abremski K (1984) Interaction of the bacteriophage P1 recombinase Cre with the recombining site loxP. Proc Natl Acad Sci USA 81:1026-1029

Hoess RH, Wierzbicki A, Abremski K (1986) The role of the loxP spacer region in P1 site-specific recombination. Nucl Acid Res 14:2287-2300

Hoff T, Schnorr KM, John Mundy J (2001) A recombinase-mediated transcriptional induction system in transgenic plants. Plant Mol Biol 45:41-49

Hohn B, Levy AA, Puchta H (2001) Elimination of selection markers from transgenic plants. Curr Opin Biotechnol 12:139-143

Horn C, Handler AM (2005) Site-specific genomic targeting in Drosophila. Proc Natl Acad Sci USA 102:12483-12488

Hu Q, Kononowicz-Hodges H, Nelson-Vasilchik K, Viola D, Zeng P, Liu H, Kausch AP, Chandlee JM, Hodges TK, Lou H (2008) FLP recombinase-mediated site-specific recombination in rice. Plant Biotechnol J 6:176-188

Huang LC, Wood EA, Cox MM (1991) A bacterial model system for chromosomal targeting. Nucl Acids Res 19:443-448

Iglesias VA, Moscone EA, Papp I, Neuhuber F, Michalowski S, Phelan T, Spiker S, Matzke M, Matzke AJM (1997) Molecular and cytogenetic analyses of stably and unstably expressed transgene loci in tobacco. Plant Cell 9:1251-1264

Iyer LM, Kumpatla SP, Chandrasekharan MB, Hall TC (2000) Transgene silencing in monocots. Plant Mol Biol 43:323-346

Jakowitsch J, Mette MF, van der Winden J, Matzke MA, Matzke AJM (1999) Integrated pararetroviral sequences define a unique class of dispersed repetitive DNA in plants. Proc Natl Acad Sci USA 96:13241-13246

Jia H, Pang Y, Chen X, Fang R (2006) Removal of the selectable marker gene from transgenic tobacco plants by expression of cre recombinase from a tobacco mosaic virus vector through agroinfection. Transgenic Res 15:375-384

Joubès J, De Schutter K, Verkest A, Inzé D, De Veylder L (2004) Conditional, recombinase-mediated expression of genes in plant cell cultures. Plant J 37:889-896 
Kellendonk C, Tronche F, Monaghan AP, Angrand PO, Stewart F, Schütz G (1996) Regulation of Cre recombinase activity by the synthetic steroid RU 486. Nucl Acids Res 24(8):1404-1411

Kempe K, Rubtsova M, Berger C, Kumlehn J, Schollmeier C, Gils M (2010) Transgene excision from wheat chromosomes by phage phiC31 integrase. Plant Mol Biol 72:673-687. doi:10.1007/ s11103-010-9606-7

Keravala A, Groth AC, Jarrahian S, Thyagarajan B, Hoyt JJ, Kirby PJ, Calos MP (2006) A diversity of serine phage integrases mediate site-specific recombination in mammalian cells. Mol Genet Genomics 276:135-146. doi:10.1007/s00438-006-0129-5

Keravala A, Lee S, Thyagarajan B, Olivares EC, Gabrovsky VE, Woodard LE, Calos MP (2009) Mutational derivatives of phiC31 integrase with increased efficiency and specificity. Mol Ther 17(1):112-120

Kerbach S, Lorz H, Becker D (2005) Site-specific recombination in Zea mays. Theor Appl Genet 11:1608-1616

Kholodii G (2001) The shuffling function of resolvases. Gene 269:121-130

Kim AI, Ghosh P, Aarron MA, Bibb LA, Jain S, Hatfull GF (2003) Mycobacteriophage Bxb1 integrates into the Mycobacterium smegmatis groELI gene. Mol Microbiol 50:463-473

Kittiwongwattana C, Lutz K, Clark M, Maliga P (2007) Plastid marker gene excision by the phiC31 phage site-specific recombinase. Plant Mol Biol 64:137-143

Kolb AF, Siddell SG (1997) Genomic targeting of a bicistronic DNA fragment by Cre-mediated site-specific recombination. Gene 203:209-216

Kolot M, Silberstein N, Yagil E (1999) Site-specific recombination in mammalian cells expressing the Int recombinase of bacteriophage HK022. Mol Biol Rep 26(207):e213

Kondrak M, van der Meer IM, Banfalvi Z (2006) Generation of Marker- and Backbone-free transgenic potatoes by site-specific recombination and a bi-functional marker gene in a non-regular one-border Agrobacterium transformation vector. Transgenic Res 15:729-737

Kopertekh L, Schiemann J (2005) Agro-infiltration as a tool for transient expression of cre recombinase in vivo. Transgenic Res 14:793-798

Kopertekh L, Juttner G, Schiemann J (2004a) Site-specific recombination induced in transgenic plants by PVX virus vector expressing bacteriophage P1 recombinase. Plant Sci 166:485-492

Kopertekh L, Juttner G, Schiemann J (2004b) PVX-Cre-mediatedmarker gene elimination from transgenic plants. Plant Mol Biol 55:491-500

Kopertekh L, Schulze k, Frolov A, Strack D, Broer I, Schiemann J (2010) Cre-mediated seed-specific transgene excision in tobacco. Plant Mol Biol 72:597-605

Korenberg JR, Chen XN, Schipper R, Sun Z, Gonsky R, Gerwehr S, Carpenter N, Daumer C, Dignan P, Disteche C (1994) Down syndrome phenotypes: the consequences of chromosomal imbalance. Proc Natl Acad Sci USA 91:4997-5001

Koskinsky HA, Lee E, Ow DW (2000) Cre-lox site-specific recombination between Arabidopsis with tobacco chromosomes. Plant J 23:715-722

Lauth M, Spreafico F, Dethleffsen K, Meyer M (2002) Stable and efficient cassette exchange under non-selectable conditions by combined use of two site-specific recombinases. Nucl Acids Res 30:e115

Lee G, Saito I (1998) Role of nucleotide sequences of loxP spacer region in Cre-mediated recombination. Gene 216:55-65

Lewandoski M, Martin GR (1997) Cre-mediated chromosome loss in mice. Nat Genet 17:223-225

Li Z, Xing A, Moon BP, Burgoyne SA, Guida AD, Lee C, Caster CS, Barton JE, Klein TM, Falco SC (2007) A Cre/loxP-mediated self-activating gene excision system to produce marker gene free transgenic soybean plants. Plant Mol Biol 65:329-341

Li Z, Xing A, Moon BP, McCardell RP, Mills K, Falco SC (2009) Site-specific integration of transgenes in soybean via recombinase-mediated DNA cassette exchange. Plant Physiol 151:10871095

Li Z, Moon BP, Xing A, Liu ZB, McCardell RP, Damude HG, Flaco SC (2010) Stacking multiple transgenes at a selected genomic site via repeated recombinase mediated DNA cassette exchanges. Plant Physiol 154:622-631

Liu HK, Yang C, Wei ZW (2005) Heat shock-regulated site-specific excision of extraneous DNA in transgenic plants. Plant Sci 168:997-1003

Logie C, Stewart AF (1995) Ligand-regulated site-specific recombination. Proc Natl Acad Sci USA 92(13):5940-5944

Louwerse JD, van Lier MC, van der Steen DM, de Vlaam CM, Hooykaas PJ, Vergunst AC (2007) Stable recombinase-mediated cassette exchange in Arabidopsis using Agrobacterium tumefaciens. Plant Physiol 145:1282-1293

Luff B, Pawlowski L, Bender J (1999) An inverted repeat triggers cytosine methylation of identical sequences in Arabidopsis. Mol Cell 3:505-511

Luo K, Duan H, Zhao D, Zheng X, Deng W, Chen Y, Stewart CN Jr, McAvoy R, Jiang X, Wu Y, He A, Pei Y, Li Y (2007) "GMGene-deletor": fused loxP-FRT recognition sequences dramatically improve the efficiency of FLP or CRE recombinase on transgene excision from pollen and seed of tobacco plants. Plant Biotechnol J 5:263-274

Lupski JR (1998) Charcot-Marie-Tooth disease: lessons in genetic mechanisms. Mol Med 4:3-11

Lutz KA, Corneille S, Azhagiri AK, Svab Z, Maliga P (2004) A novel approach to plastid transformation utilizes the phiC31 phage integrase. Plant J 37:906-913

Lyznik LA, Rao KV, Hodges TK (1996) FLP-mediated recombination of FRT sites in the maize genome. Nucl Acids Res 24:3784-3789

Malchin N, Molotsky T, Yagil E, Kotlyar AB, Kolot M (2008) Molecular analysis of recombinase-mediated cassette exchange reactions catalyzed by integrase of coliphage HK022. Res Microbiol 1:e8

Maqbool SB, Chritou P (1999) Multiple traits of agronomic importance in transgenic indica rice plants: analysis of transgene integration patterns, expression levels and stability. Mol Breed 5:471-480

Matsunaga E, Sugita K, Ebinuma H (2002) Asexual production of selectable marker-free transgenic woody plants, vegetatively propagated species. Mol Breed 10:95-106

Medberry SL, Dale P, Qin M, Ow DW (1995) Intra-chromosomal rearrangements generated by Cre-lox site-specific recombination. Nucl Acids Res 23:485-490

Metzger D, Clifford J, Chiba H, Chambon P (1995) Conditional sitespecific recombination in mammalian cells using a liganddependent chimeric Cre recombinase. Proc Natl Acad Sci USA 92(15):6991-6995

Meyer P (2000) Transcriptional transgene silencing and chromatin component. Plant Mol Biol 43:221-234

Mlynárová L, Conner AJ, Nap JP (2006) Directed microsporespecific recombination of transgenic alleles to prevent pollenmediated transmission of transgenes. Plant Biotechnol J 4:445-452

Moeller L, Wang K (2008) Engineering with precision: tools for the new generation of transgenic crops. Bioscience 58:391-401

Moon HS, Li Y, Stewart CN (2009) Keeping the genie in the bottle: transgene biocontainment by excision in pollen. Trends Biotechnol 28(1):3-8 
Mouw KW, Rowland SJ, Gajjar MM, Boocock MR, Stark WM, Rice PA (2008) Architecture of a serine recombinase-DNA regulatory complex. Mol Cell 30:145-155

Murai N, Kemp JD, Sutton DW, Murray MG, Slightom JL, Merlo DJ, Reichert NA, Sengupta-Gopalan C, Stock CA, Barker RF, Kemp JD, Hall TC (1983) Phaseolin gene from bean is expressed after transfer to sunflower via tumor-inducing plasmid vectors. Science 222:476-482

Muskens MWM, Vissers APA, Mol JNM, Kooter JM (2000) Role of inverted DNA repeats in transcriptional and posttranscriptional gene silencing. Plant Mol Biol 43:243-260

Nanto K, Ebinuma H (2008) Marker-free site-specific integration plants. Transgenic Res 17:337-344

Nanto K, Yamada-Watanabe K, Ebinuma H (2005) Agrobacteriummediated RMCE approach for gene replacement. Plant Biotechnol J 3:203-214

Nanto K, Sato K, Katayama Y, Ebinuma H (2009) Expression of a transgene exchanged by the recombinase-mediated cassette exchange (RMCE) method in plants. Plant Cell Rep 28(5):777-785

O'Gorman S, Fox DT, Wahl GM (1991) Recombinase-mediated gene activation and site-specific integration in mammalian cells. Science 251:1351-1355

Olivares EC, Hollis RP, Calos MP (2001) Phage R4 integrase mediates site-specific integration in human cells. Gene 278:167-176

Onouchi H, Yokoi K, Machida C, Matsuzaki H, Oshima Y et al (1991) Operation of an efficient site-specific recombination system of Zygosaccharomyces rouxii in tobacco cells. Nucl Acids Res 19:6373-6378

Ou HL, Huang Y, Qu LJ, Xu M, Yan JB, Ren ZR, Huang SZ, Zeng YT (2009) A phiC31 integrase-mediated hotspot in favor of transgene expression exists in bovine genome. FEBS $\mathrm{J}$ 276:155-163

Ow DW (2005) Transgene management via multiple site-specific recombination systems. In Vitro Cell Dev Biol Plant 41:213-219

Ow DW (2007) GM maize from site-specific recombination technology, what next? Curr Opin Biotechnol 18:115-120

Peitz M, Pfannkuche K, Rajewsky K, Edenhofer F (2002) Ability of the hydrophobic FGF and basic TAT peptides to promote cellular uptake of recombinant Cre recombinase: a tool for efficient genetic engineering of mammalian genomes. Proc Natl Acad Sci USA 99(7):4489-4494

Qin M, Bayley C, Stockton T, Ow DW (1994) Cre recombinasemediated site-specific recombination between plant chromosomes. Proc Natl Acad Sci USA 91:1706-1710

Radhakrishnan P, Srivastava V (2005) Utility of the FLP-FRT recombination system for genetic manipulation of rice. Plant Cell Rep 23:721-726

Ramierez-Solis R, Liu P, Bradley A (1995) Chromosome engineering in mice. Nature 378:720-724

Rubtsova M, Kempe K, Gils A, Ismagul A, Weyen J, Gils M (2008) Expression of active Streptomyces phage phiC31 integrase in transgenic wheat plants. Plant Cell Rep 27:1821-1831

Russell SH, Hoopes JL, Odell JT (1992) Directed excision of a transgene from the plant genome. Mol Gen Genet 234:49-59

Russell JP, Chang DW, Tretiakova A, Padidam M (2006) Phage Bxb1 integrase mediates highly efficient. Biotechniques 40:460-464

Sarkis GJ, Murley LL, Leschziner AE, Boocock MR, Stark WM, Grindley ND (2001) A model for the gamma delta resolvase synaptic complex. Mol Cell 8:623-631

Sauer B (1987) Functional expression of the cre-lox site-specific recombination system in the yeast Saccharomyces cerevisiae. Mol Cell Biol 7(6):2087-2096

Sauer B (1996) Cre/lox recombination permits selective site-specific DNA targeting to both a natural and an engineered site in the yeast genome. Nucl Acids Res 24:4608-4613
Sauer B, Henderson N (1990) Targeted insertion of exogenous DNA into the eukaryotic chromosome by the cre recombinase. New Biol 2:441-449

Schlake T, Bode J (1994) Use of mutated FLP recognition target (FRT) sites for the exchange of expression cassettes at defined chromosomal loci. Biochemistry 33:12746-12751

Schwikardi M, Droge P (2000) Site-specific recombination in mammalian cells catalyzed by gammadelta resolvase mutants: implications for the topology of episomal DNA. FEBS Lett 471:147-150

Sclimenti CR, Thyagarajan B, Calos MP (2001) Directed evolution of a recombinase for improved genomic integration at a native human sequence. Nucl Acids Res 29(24):5044-5051

Seibler J, Bode J (1997) Double -reciprocal crossover mediated by FLP-recombinase: a concept and an assay. Biochemistry 36:1740-1747

Seibler J, Schubeler D, Fiering S, Groudine M, Bode J (1998) DNA cassette exchange in ES cells mediated by FLP recombinase: an efficient strategy for repeated modification of tagged loci by marker-free constructs. Biochemistry 37:6229-6234

Selker EU (1999) Gene silencing: repeats that count. Cell 97:157-160

Senecoff JF, Rossmeissl PJ, Cox MM (1988) DNA recognition by the FLP recombinase of the yeast $2 \mathrm{~m}$ plasmid: a mutational analysis of the FLP binding site. J Mol Biol 201:405-421

Siegel RW, Jain R, Bradbury A (2001) Using an in vivo phagemid system to identify non-compatible loxP sequences. FEBS Lett 505:467-473

Smith AJH, De Sousa MA, Kwabi-Addo B, Heppell-Parton A, Impey H, Rabbitts P (1995) Balanced chromosome translocations between e-myc with immunoglobin heavy chain chromosomes 12 and 15. Nat Genet 9:376-385

Sreekala C, Wu L, Gu K, Wang D, Tian D, Yin Z (2005) Excision of a selectable marker in transgenic rice (Oryza sativa L.) using a chemically regulated Cre/loxP system. Plant Cell Rep 24:86-94

Srivastava V, Gidoni D (2010) Site-specific gene integration technologies for crop improvement. In Vitro Cell Dev Biol Plant 46(3):219-232

Srivastava V, Ow DW (2001) Single-copy primary transformants of maize obtained through the co-introduction of a recombinaseexpressing construct. Plant Mol Biol 46:561-566

Srivastava V, Ow DW (2002) Biolistic mediated site-specific integration in rice. Mol Breed 8:345-350

Srivastava V, Ow DW (2003) Rare instances of Cre-mediated deletion product maintained in transgenic wheat. Plant Mol Biol 52:661-668

Srivastava V, Anderson OD, Ow DW (1999) Single-copy transgenic wheat generated through the resolution of complex integration patterns. Proc Natl Acad Sci USA 96:11117-11121

Srivastava V, Ariza-Nieto M, Wilson AJ (2004) Cre-mediated sitespecific gene integration for consistent transgene expression in rice. Plant Biotechnol J 2:169-179

Stoll S, Ginsburg DS, Calos MP (2002) Phage TP901-1 site-specific integrase functions in human cells. J Bacteriol 184:3657-3663

Sugita K, Matsunaga E, Ebinuma H (1999) Effective selection system for generating marker-free transgenic plants independent of sexual crossing. Plant Cell Rep 18:941-947

Sugita K, Kasahara T, Matsunaga E, Ebinuma H (2000a) A transformation vector for the production of marker-free transgenic plants containing a single copy transgene at high frequency. Plant J 22(5):461-469

Sugita K, Matsunaga E, Kasahara T, Ebinuma H (2000b) Transgene stacking in plants in the absence of sexual crossing. Mol Breed 6:529-536

Takahashi T, Naito S, Komeda Y (1992) Isolation and analysis of the expression of two genes for the 81-kilodalton heat-shock proteins from Arabidopsis. Plant Physiol 99:383-390 
Thomason LC, Calendar R, Ow DW (2001) Gene insertion and replacement in Schizosaccharomyces pombe mediated by the Streptomyces bacteriophage phiC31 site-specific recombination system. Mol Genet Genomics 265:1031-1038

Thomson JG, Ow DW (2006) Site-specific recombination systems for the genetic manipulation of eukaryotic genomes. Genesis 44:465-476

Thomson JG, Rucker EB 3rd, Piedrahita JA (2003) Mutational analysis of $\operatorname{lox} P$ sites for efficient Cre-mediated insertion into genomic DNA. Genesis 36:162-167

Thomson JG, Yau YY, Blanvillain R, Chiniquy D, Thilmony R, Ow DW (2009) ParA resolvase catalyzes site-specific excision of DNA from the Arabidopsis genome. Transgenic Res 18(2):237-248

Thomson JG, Chan R, Thilmony R, Yau Y-Y, Ow DW (2010) PhiC31 recombination system demonstrates heritable germinal transmission of site-specific excision from the Arabidopsis genome. BMC Biotechnol 10:17. doi:10.1186/1472-6750-10-17

Thorpe HM, Smith MC (1998) In vitro site-specific integration of bacteriophage DNA catalyzed by a recombinase of the resolvase/ invertase family. Proc Natl Acad Sci USA 95(10):5505-5510

Thorpe HM, Wilson SE, Smith MC (2000) Control of directionality in the site-specific recombination system of the Streptomyces phage phiC31. Mol Microbiol 38:232-241

Thyagarajan B, Guimarães MJ, Groth AC, Calos MP (2000) Mammalian genomes contain active recombinase recognition sites. Gene 244(1-2):47-54

Thyagarajan B, Olivares EC, Hollis RP, Ginsburg DS, Calos MP (2001) Site-specific genomic integration in mammalian cells mediated by phage phiC31 integrase. Mol Cell Biol 21(12): 3926-3934

Uemura M, Niwa Y, Kakazu N, Adachi N, Kinoshita K (2010) Chromosomal manipulation by site-specific recombinases and fluorescent protein-based vectors. PLoS ONE 5(3):e9846. doi: 10.1371/journal.pone.0009846

Van Deursen J, Fornerod M, Van Rees B, Grosveld G (1995) Cremediated site-specific translocation between nonhomologous mouse chromosomes. Proc Natl Acad Sci USA 92:7376-7380

Vergunst AC, Hooykaas PJ (1998) Cre/lox-mediated site-specific integration of Agrobacterium T-DNA in Arabidopsis thaliana by transient expression of cre. Plant Mol Biol 38:393-406
Vergunst AC, Jansen LE, Hooykaas PJ (1998) Site-specific integration of Agrobacterium T-DNA in Arabidopsis thaliana mediated by Cre recombinase. Nucl Acids Res 26:2729-2734

Vergunst AC, Schrammeijer B, den Dulk-Ras A, De Vlaam CMT, Regensburg-Tuink TJG, Hooykaas PJJ (2000) Vir B/D4-dependent protein translocation from Agrobacterium into plant cells. Science 290:979-982

Verweire D, Verleyen K, De Buck S, Claeys M, Angenon G (2007) Marker-free transgenic plants through genetically programmed auto-excision. Plant Physiol 145:1220-1231

Wang Y, Chen B, Hu Y, Li J, Lin Z (2005) Inducible excision of selectable marker gene from transgenic plants by the cre/lox sitespecific recombination system. Transgenic Res 14:605-614

Watson AT, Garcia V, Bone N, Carr AM, Armstrong J (2008) Gene tagging and gene replacement using recombinase-mediated cassette exchange in Schizosaccharomyces pombe. Gene 407:63-74

Westerman KA, Leboulch P (1996) Reversible immortalization of mammalian cells mediated by retroviral transfer and site-specific recombination. Proc Natl Acad Sci USA 93:8971-8976

Yau Y-Y, Wang Y, Thomson J, Ow D (2010) Method for Bxb1mediated site-specific integration in planta. In: Birchler JA (ed) Plant chromosome engineering: methods in molecular biology. Humana Press, Clifton (in press)

Zhang W, Subbarao S, Addae P, Shen A, Armstrong C, Peschke V, Gilbertson L (2003) Cre/lox-mediated marker gene excision in transgenic maize (Zea mays L.) plants. Theor Appl Genet 107:1157-1168

Zhang Y, Li H, Ouyang B, Lu Y, Ye Z (2006) Chemical-induced autoexcision of selectable markers in elite tomato plants transformed with a gene conferring resistance to lepidopteran insects. Biotechnol Lett 28:1247-1253

Zheng B, Sage M, Cai WW, Thompson DM, Tausanli BC, Cheah YC, Bradley A (1999) Engineering a mouse balancer chromosome. Nat Genet 22:375-378

Zuo J, Niu Q-W, Møller SG, Chua N-H (2001) Chemical-regulated, site-specific DNA excision in transgenic plants. Nat Biotechnol 19:157-161 